\title{
Search and concealment strategies in the spatiotemporal domain
}

\author{
Motohiro Ito $^{1,2}$ Jun-ichiro Kawahara ${ }^{1}$ \\ Published online: 12 February 2020 \\ (C) The Psychonomic Society, Inc. 2020
}

\begin{abstract}
Although visual search studies have primarily focused on search behavior, concealment behavior is also important in the real world. However, previous studies in this regard are limited in that their findings about search and concealment strategies are restricted to the spatial (two-dimensional) domain. Thus, this study evaluated strategies during three-dimensional and temporal (i.e., spatiotemporal) search and concealment to determine whether participants would indicate where they would hide or find a target in a temporal sequence of items. The items were stacked in an upward (Experiments 1-3) or downward (Experiment 4) direction and three factors were manipulated: scenario (hide vs. seek), partner type (friend vs. foe), and oddball (unique item in the sequence; present vs. absent). Participants in both the hide and seek scenarios frequently selected the oddball for friends but not foes, which suggests that they applied common strategies because the oddball automatically attracts attention and can be readily discovered by friends. Additionally, a principle unique to the spatiotemporal domain was revealed, i.e., when the oddball was absent, participants in both scenarios frequently selected the topmost item of the stacked layer for friends, regardless of temporal order, whereas they selected the first item in the sequence for foes, regardless of the stacked direction. These principles were not affected by visual masking or number of items in the sequence. Taken together, these results suggest that finding and hiding positions in the spatiotemporal domain rely on the presence of salient items and physical accessibility or temporal remoteness, according to partner type.
\end{abstract}

Keywords Visual search $\cdot$ Finding and hiding strategies $\cdot$ Spatiotemporal domain

Previous studies investigating visual search have primarily focused on search behaviors (Awh, Belopolsky, \& Theeuwes, 2012; Carrasco, 2011), which seems reasonable because visual search is indispensable to everyday situations such as looking for a house key on a desk or identifying desired products in a supermarket. Reflecting these behaviors

on cognitive researches, observers search for a visual target amidst a variable number of distractors during an ordinary spatial visual search task (Wolfe \& Horowitz, 2017). However, visual attention can also be allocated in time as well as space (Coull, Frith, Büchel, \& Nobre, 2000; Mento \& Tarantino, 2015). A popular paradigm known as rapid serial visual presentation is often used to manipulate the factors involved in the allocation of attention in the temporal domain (e.g., Martens \& Wyble, 2010; Raymond, Shapiro, \& Arnell, 1992). To achieve current goals, it is necessary to select taskrelevant objects and spatial and/or temporal locations while restricting the processing of irrelevant information because the visual system is limited in terms of its capacity to recognize many stimuli at once (Lamy, Leber, \& Egeth, 2012; Rohenkohl, Coull, \& Nobre, 2011).

Research on visual attention has examined a wide range of factors that improve or impair visual search performance by manipulating the visual properties of targets and controlling the allocation of spatial and/or temporal attention (Pastukhov, Vonau, Stonkute, \& Braun, 2013; Smilek, Weinheimer, Kwan, Reynolds, \& Kingstone, 2009; Wolfe \& Horowitz, 2017). For example, the saliency of a target can influence search

1 Department of Psychology, Hokkaido University, N10W7, Kita, Sapporo 060-0810, Japan

2 Japan Society for the Promotion of Science, Tokyo, Japan 
performance. Generally, a search is more efficient when target saliency is high compared to when the saliencies of the target and non-targets are similar (Liesefeld, Moran, Usher, Müller, \& Zehetleitner, 2016; Smilek et al., 2009). Furthermore, due to low levels of resource allocation, target identifications are impaired during a visual search in the temporal domain when the target is embedded within a rapid sequence of non-target letters that appear relatively early in the sequence (Ariga \& Yokosawa, 2008; Kranczioch \& Bryant, 2011).

Several recent studies have investigated concealment behavior by human adults in addition to search behavior (Anderson, Foulsham, Nasiopoulos, Chapman, \& Kingstone, 2014; Legge et al., 2012; Smilek et al., 2009; Street, Bischof, \& Kingstone, 2018; Talbot, Legge, Bulitko, \& Spetch, 2009). In a real-world situation, humans sometimes display or hide an object (e.g., a Christmas present or recommended products) so that others (e.g., family members or customers) will find it whereas others (e.g., thieves) will not be able to find it (e.g., a house key or a bankbook). In fact, there is a close relationship between visual search and concealment. For example, concealed positions are applied to the basic strategies of visual search, i.e., observers can appropriately hide a visual target from others based on their knowledge of the visual search difficulties that will be encountered by finders (Legge et al., 2012; Smilek et al., 2009). Therefore, further elucidating visual concealment behavior will be important for understanding the human cognitive processes involved in visual search. Typically, visual search and concealment studies are divided into experiments using a classical simple array, such as a homogenous or pop-out display (Anderson et al., 2014; Street et al., 2018), or by using complex visual scenes or stimuli, such as a room or emotional faces (Legge et al., 2012; Smilek et al., 2009; Talbot et al. 2009). The present study explored strategies for hiding and finding using the former standard experimental situation.

To investigate hiding and finding strategies in the spatial (two-dimensional) domain, Anderson et al. (2014) and Street et al. (2018) developed a novel task, the hide-find Paradigm, which is a kind of treasure-hunting task that introduces partner type (e.g., friend or foe) as a dependent variable. In this task, participants in the friend context (or foe, who was a fictional opponent) were either instructed to indicate where they would hide a critical item (e.g., a house key) in spatially distributed visual arrays $(4 \times 4$ grid of boxes) or asked to find a target that had been hidden by a friend or a foe in a block-wise manner. In other words, if the partner was a friend, then participants in the hide scenario chose a target position so that friends would find the target whereas participants in the seek scenario chose a target position that had been hidden by friends so that the participants would find it. In contrast, if the partner was a foe, the participants in the hide scenario chose a target position so that the foe would not find the target, whereas participants in the seek scenario chose a target position that had been hidden by the foe so that the participants would not find it. Additionally, under these task circumstances, the visual arrays were manipulated to produce two conditions: homogenous displays, which consisted of visual arrays of uniform boxes (i.e., oddball-absent condition), and pop-out displays, which consisted of visual arrays with a unique box (i.e., oddballpresent condition). Then, the frequencies at which the participants selected the targets in each spatial location were recorded.

Importantly, spatial principles based on partner type (friend or foe) are observed when participants engage in spatial hide/ seek tasks (Anderson et al., 2014; Street et al., 2018). For instance, under the oddball-present condition, participants in both the hide and seek scenarios are more likely to select the oddball when the partner is a friend whereas they avoid selecting the oddball when the partner is a foe. These results indicate that participants execute strategies assuming that the oddball would capture the attention of friends (or foes) and, thus, be easily discovered by friends (or foes). Importantly, under the oddball-absent condition, participants in both the hide and seek scenarios are likely to select the items at spatially corner positions of visual arrays when the partner is a friend whereas they are more likely to select items at centrally converged positions when the partner is a foe. Anderson et al. (2014) suggested that the former result is consistent with natural intuitions during search and concealment (Smilek et al., 2009) such that placing a critical target at edge positions leads to easier search because placing objects at the edges provides a salient feature that supports pop-out detection. Additionally, these authors suggested that the latter result reflects the notion that a critical target is well camouflaged when surrounded by various items. Taken together, from the perspective of the fundamental principles of hiding and finding, these results suggest that participants are more likely to hide and search for an item that would attract attention physically and spatially for/from friends whereas participants would hide and search for an item that is not salient for/from foes. However, the current explanations of the principles underlying search and concealment remain insufficient because previous studies have primarily focused on spatial factors and left temporal factors relatively unexplored (e.g., the presentation order of items).

Thus, the present study investigated hiding and finding in a temporal domain and aimed to determine whether observers would indicate where they would find or hide a critical item embedded within a temporal sequence. More specifically, the hide-find paradigm that has, to date, been exclusively used for hiding and finding in the spatial (two-dimensional) domain (Anderson et al., 2014; Street et al., 2018) was modified to assesses these circumstances in the temporal domain when items appeared sequentially. Additionally, the present paradigm manipulated partner type (i.e., the interpersonal relationship between observers and fictional opponents: friend vs. 
foe) and the presence or absence of a unique item in the sequence (oddball). Because the fundamental principles of hiding and finding in the spatial domain can be applied to those in the temporal domain, it can be expected that participants will hide and find an item that would attract attention for/from friends whereas they will hide and search for the item that is not salient for/from foes. Therefore, it was predicted in the present study that the participants would be more likely to select the oddball (when present) for friends than for foes.

Importantly, the present study also focused on situations in which participants indicated where they would hide or find a target within a temporal sequence of items when the oddball was absent (i.e., homogenous display). If the spatial principles associated with hiding and seeking (Anderson et al., 2014) also apply to search and concealment in sequentially presented items, then the participants would consider the first and last items to be more salient than other items because the first and last items in a temporal sequence are homologous to items located at the edge positions in a spatial array. Similarly, the items that were not first or last in a temporal sequence should be equivalent to those placed centrally or those that are camouflaged in a spatial array. Moreover, the first and last items should be more salient than the other items due to serial position effects, i.e., the primacy and recency effects (Grenfell-Essam \& Ward, 2012; Murdock Jr, 1962). Therefore, it was expected in the present study that the first and last items would be more likely to be selected for a friend rather than a foe. The present study also examined the effects of visual masking (Experiment 2) and the specific number of items in a sequence (Experiment 3 ) on selections during hiding and finding to distinguish whether the selections were made due to perceptual visibility or temporal factors.

\section{Experiment 1}

Experiment 1 was conducted to determine where participants would hide or find a target within a sequence of items that was stacked in an upward direction and whether the hiding/finding locations would vary depending on partner type (friend vs. foe) and the presence or absence of an oddball. Specifically, the participants viewed a temporal sequence of four items as if a suit of flipped playing cards was displayed sequentially. Then, each participant hid or searched for a critical target so that a fictional partner would (or would not) find the target or the target was hidden by a partner so that the participant would (or would not) find it. It was predicted that the participants would hide and find the target that attracted attention physically and spatially and/or temporally for/from friends whereas they would hide and search for a target that was not salient for/ from foes. In other words, the participants would select the oddball for friends but select the non-oddball for foes. Furthermore, it was predicted that if the spatial principles and serial position effects apply to search and concealment in the present case, then the first and last (fourth) items would be selected for friends whereas the other items would be selected for foes under the oddball-absent condition.

\section{Method}

Participants The present study recruited 40 undergraduate and graduate students (19 females, between 18 and 32 years of age) from the participant pool at Hokkaido University, who participated in exchange for pay or course credit. Half of the participants (seven females, mean age $=19.7$ years) were randomly assigned to the hide scenario while the other half (12 females, mean age $=21.1$ years) were assigned to the seek scenario; this sample size was chosen based on those used in previous studies (Anderson et al., 2014; Street et al., 2018). All participants in this and the subsequent experiments reported normal or corrected-to-normal visual acuity and provided written informed consent according to approval by the Center for Experimental Research in Social Sciences of Hokkaido University.

Apparatus and stimuli All stimuli were presented on a 24-inch LCD monitor (100-Hz refresh rate, $1920 \times 1080$ pixels) controlled by a PC/AT-compatible computer operating with Linux, MATLAB, and Psychophysics Toolbox (Brainard, 1997; Kleiner, Brainard, \& Pelli, 2007; Pelli, 1997). The viewing distance was approximately $57 \mathrm{~cm}$, all stimuli were displayed on a black background, and all responses were collected via a keyboard connected to the computer.

Participants viewed a sequence of four white cards with green polygon patterns that looked like the backs of playing cards (Fig. 1). Each item subtended $22.3^{\circ}$ in height and up to $15.0^{\circ}$ in width. Most items flew from the bottom right of the screen to the center of the screen whereas the oddballs flew from the bottom left to the center. The items were stacked in an upward direction so that newly appeared items were placed over the old items. Each sequence lasted $3000 \mathrm{~ms}$ ( $750 \mathrm{~ms}$ per card).

Design The present experiment employed a $2 \times 2 \times 2$ factorial design with one between-subjects factor, task scenario (hide vs. seek), and two within-subject factors, partner type (social context: friend vs. foe) and oddball (present vs. absent). In total, the experimental session consisted of 12 blocks and 144 trials. Half of the blocks were assigned to the friend context and the other half of the blocks were assigned to the foe context. The order alternated between the friend and foe contexts, and the initial condition (friend or foe) was counterbalanced within each task scenario group. Each block consisted of 12 trials and included four trials under the oddball-absent condition and eight trials under the oddballpresent condition. The oddball was presented twice in each 
Until the key press

Select the

position where

you would hide

Blank (500ms)

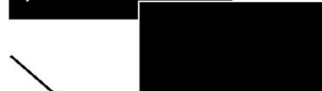

\section{$1^{\text {st }}$ item}

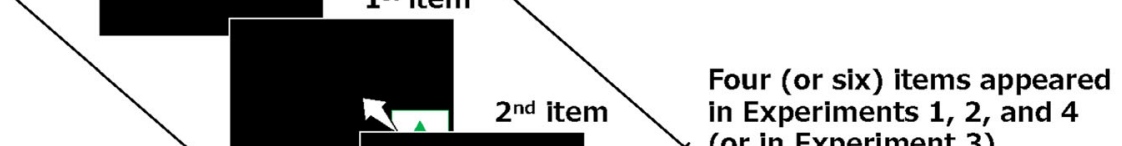

(or in Experiment 3).

Fig. 1. Semantic example of a single trial in the revised hide-find paradigm within the temporal domain (Experiments 1-4). All items in the sequence moved from the bottom left or right of the screen to the center of the screen when no oddball was present. When an oddball was present, one of the sequence items moved from the bottom right (or left) of the screen to the center of the screen while the remaining items moved from the bottom left (or right) to the center. In Experiments 2-4 but not

of the four possible temporal locations of the sequence and the order of trials was randomly determined within each block.

Procedure The participants were asked to indicate where they would hide or find (i.e., task scenario) an item embedded within a temporal sequence of cards when dealing with a friend or foe (i.e., partner type; see instructions in Table 1). In the hide scenario, participants were asked to select a temporal position to conceal an item so that a friend could choose or so that a foe could not choose it. In the seek scenario, participants were asked to select a temporal position of an item hidden by a friend so that the participant would find it or the

Table 1. Different instructions across the task scenario and partner type conditions

\begin{tabular}{|c|c|c|}
\hline Scenario & $\begin{array}{l}\text { Partner } \\
\text { type }\end{array}$ & Instructions \\
\hline Hide & Friend & $\begin{array}{l}\text { One of your cards is a winner, and the rest are losers. A fictional opponent draws a card, wanting to choose the winning card. You } \\
\text { want to hide this card in one of the four temporal positions so that your opponent will find it. Select the position where you } \\
\text { would hide the card. }\end{array}$ \\
\hline Hide & Foe & $\begin{array}{l}\text { One of your cards is a winner, and the rest are losers. A fictional opponent draws a card, wanting to choose the winning card. You } \\
\text { want to hide this card in one of the four temporal positions so that your opponent will not find it. Select the position where you } \\
\text { would hide the card. }\end{array}$ \\
\hline Seek & Friend & $\begin{array}{l}\text { One of cards held by your fictional opponent is a winner, and the rest are losers. You draw a card, wanting to choose the winning } \\
\text { card. Your opponent wants to hide the card in one of the four temporal positions so that you will find it. Select the position } \\
\text { where you would find the card. }\end{array}$ \\
\hline Seek & Foe & $\begin{array}{l}\text { One of cards held by your fictional opponent is a winner, and the rest are losers. You draw a card, wanting to choose the winning } \\
\text { card. Your opponent wants to hide the card in one of the four temporal positions so that you will not find it. Select the position } \\
\text { where you would find the card. }\end{array}$ \\
\hline
\end{tabular}


position of an item that a foe had hidden, so that they would not find it.

Each trial began with written instructions (e.g., "Select the position where you would hide an object so that a foe could not find it" in Japanese) in the center of the screen and then participants initiated the trial by pressing the space bar. After a 500-ms interval with a blank screen, the temporal sequence started. All items of the sequence except for one slid from the bottom right of the screen to the center of the screen when the no-oddball condition was present. The unique item in the sequence (as an oddball), if any, slid into the display from the bottom left of the screen to the center of the screen; this exception occurred only in the oddball-present condition. The cards that slid into the display were stacked upward in the center of the display. After the presentation of the four items in the sequence, the participants guessed and reported the temporal position of the critical item by pressing a corresponding key on the numeric keypad $(1,2,3$, or 4$)$ with no time constraints.

\section{Results}

Oddball condition Figure 2 displays the mean frequencies of selecting the oddball item in each temporal position according to scenario (hide vs. seek) and partner type (friend vs. foe). To assess whether the participants were biased toward oddball items, the frequencies of selecting the oddball for the task scenario and partner type conditions were compared using an analysis of variance (ANOVA) with task scenario as a between-subjects factor and partner type as a within-subjects factor. There was a main effect of task scenario $(F(1,38)=$ 4.33, $\left.p=.04, \eta_{\mathrm{p}}{ }^{2}=.10\right)$, which indicates that the participants more frequently selected the oddball in the seek scenario than in the hide scenario. Additionally, the main effect of partner type was significant $\left(F(1,38)=52.06, p<.001, \eta_{\mathrm{p}}{ }^{2}=.58\right)$, which indicates that the participants more frequently selected the oddball for friends than for foes in both the hide and seek scenarios. The interaction between task scenario and partner type was not significant $\left(F(1,38)=0.67, p=.42, \eta_{\mathrm{p}}{ }^{2}=.02\right)$.

No-oddball condition The frequencies of the item selections for each scenario and partner type were also compared when the oddball was absent. Chi-square analyses were conducted for each condition to examine whether the temporal positions of the selected items (e.g., first, second, third, and fourth items) were biased. Figure 3 displays the mean frequencies of selecting one of the four possible temporal positions for each partner type (friend or foe) and scenario (hide or seek). Chi-square tests revealed that the selections in the absence of the oddball were significantly biased by the temporal position when hiding for a friend (Fig. 3, top left; $\chi^{2}(3)=95.03, p<$ $.001, w=0.45)$. Specifically, multiple comparisons assessed using binomial tests revealed that the fourth item was most frequently selected compared to the other temporal locations ( $p s<.001)$ and that the first item was least frequently selected relative to the other temporal locations ( $p s<.001)$ (the $p$ values included in all of the following analyses were adjusted based on the study performed by Benjamini \& Hochberg, 1995). The selection frequencies between the second and third items did not differ $(p=.31)$.

Similar Chi-square tests were applied to assess the probabilities of selections when hiding for a foe. These tests revealed a significant effect of temporal position (Fig. 3, top right; $\left.\chi^{2}(3)=185.88, p<.001, w=0.62\right)$ such that the pattern of results contrasted sharply with the findings obtained when hiding for a friend. Specifically, the first item was most frequently selected $(p s<.001)$ whereas the third item was least frequently selected relative to the other items $(p s<.001)$. Additionally, the fourth item was selected more frequently than the second and third items $(p s<.03)$.

Chi-square tests evaluating the seek scenario in the friend condition indicated that the selection was significantly biased (Fig. 3, bottom left; $\chi^{2}(3)=330.32, p<.001, w=0.83$ ) such that the fourth item was most frequently selected $(p s<.001)$ whereas the third item was least frequently selected $(p s<.03)$. The selection frequencies between the first and second items did not differ $(p=.46)$.

Finally, Chi-square tests applied to the seeking from a foe condition indicated a significant effect of temporal position (Fig. 3, bottom right; $\chi^{2}(3)=70.15, p<.001, w=0.38$ ). Specifically, the first item was most frequently selected ( $p \mathrm{~s}<$ .001 ) whereas the fourth item was least frequently selected ( $p$ s $<.03)$. The selection frequencies between the second and third items did not differ $(p=.78)$.

\section{Discussion}

As predicted, the participants more frequently selected the oddball for friends but more frequently avoided the oddball for foes, regardless of the hide or seek scenario. These strategies were identical to those used for search and concealment in the spatial domain (Anderson et al., 2014; Street et al., 2018). In other words, the participants applied the natural intuition (Smilek et al., 2009) that an oddball physically attracts attention and can be easy to discover for friends. This idea was originally observed in spatial search tasks (Anderson et al., 2014) and was shown to be applicable to the present temporal search task, even though the physical circumstances substantially differed. It is possible that the mere presence of an oddball and its conceptual similarity were sufficient for the participants to adopt the metacognition that a salient item in the present context would attract attention and, thus, be easily discovered by others in the temporal domain. Interestingly, participants in the seek condition selected the oddball more frequently than those in the hide condition (Fig. 2, top left vs. bottom left), which is consistent with previous findings 
oddball-present condition
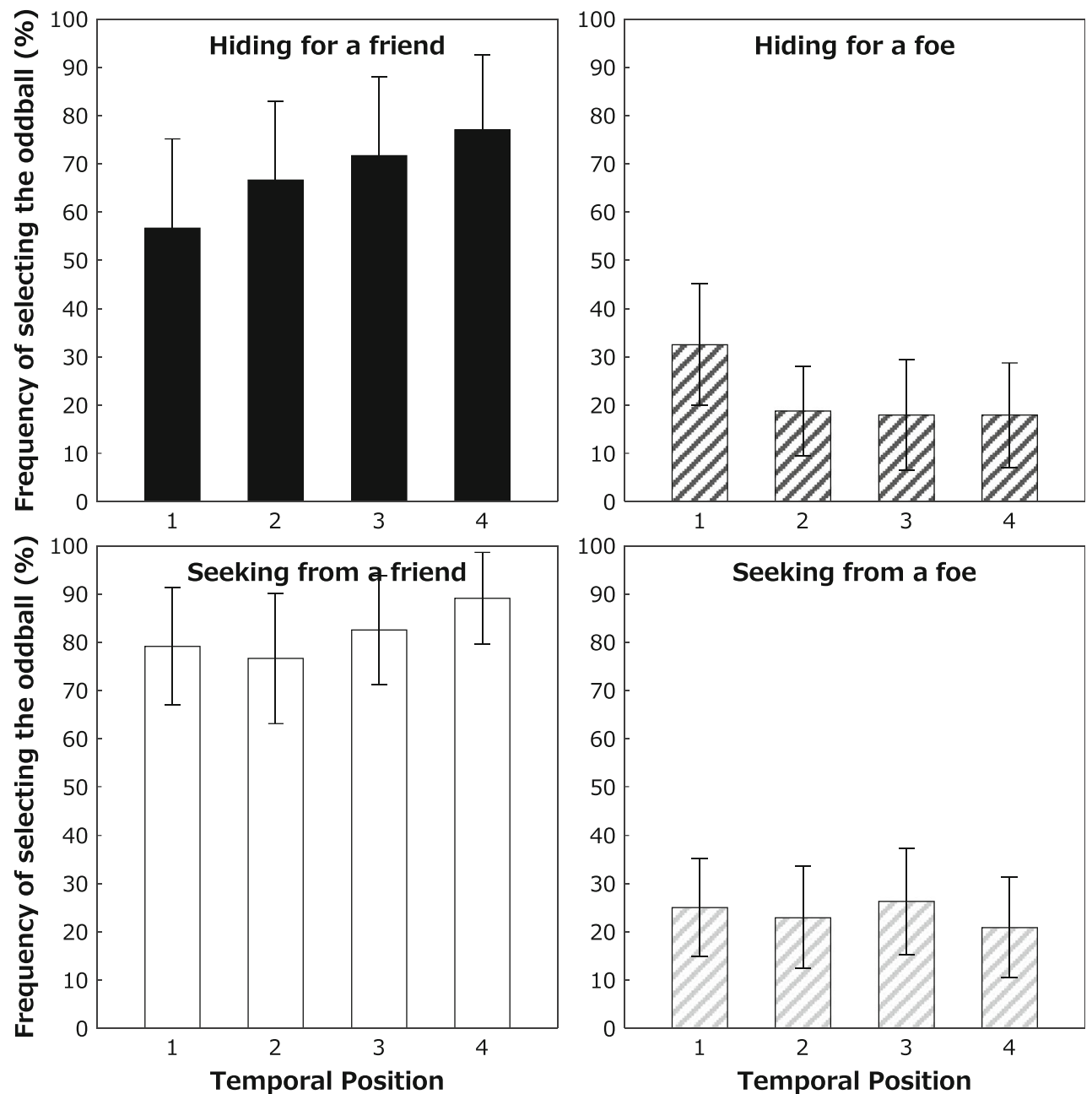

Fig. 2. Mean frequencies of selecting the oddball in each temporal position according to each task scenario (hide or seek) and partner type (friend or foe) in Experiment 1. Error bars show 95\% confidence intervals

(Anderson et al., 2014; Smilek et al., 2009) and suggests that hiding is a more complex process than finding.

The results in the no-oddball condition were straightforward. Participants chose the fourth item most frequently and the first item least frequently for a friend relative to the other items, regardless of the hide or seek scenario. However, the pattern dramatically flipped for a foe such that participants chose the first item most frequently and the fourth item least frequently regardless of task scenario. These patterns of results cannot be explained by the primacy and recency effects of short-term memory because the biased choices of the first and fourth items were determined by the scenario (i.e., for a friend or foe). It is possible that the biased selections of sequentially presented items could be explained by the idea that the spatial (e.g., three-dimensional) structures of the items and their accessibility would be critical for selection. In fact, there is a close relationship between action and cognition (Hommel, 2015; Pratt \& Abrams, 1994; Shin, Proctor, \& Capaldi, 2010; Solman, Cheyne, \& Smilek, 2012; Solman, Hickey, \&
Smilek, 2014; Street et al., 2018; Tipper, Lortie, \& Baylis, 1992). For example, Street et al. (2018) found that, when participants selected items using a touch screen, they were more likely to select items based on a belief regarding the sitting position of a friend. More specifically, the participants selected closer items because they had shifted their own perspective to that of a friend, so that the target would be easy for the friend to reach. Similarly, the search was delayed and missed when participants unpacked heaps of items and searched for a particular target in such a three-dimensional layout relative to when the participants searched for the target in a typical two-dimensional layout of spatially distributed items (Solman et al., 2012, 2014). The items in Experiment 1 in the present study constituted a three-dimensional structure and stacked upward in order and, thus, the first item was the bottommost card and the fourth item was the topmost card in the stack. Therefore, this spatial structure would imply differential accessibilities of these items and could have resulted in the fourth and topmost item being most accessible whereas the 
oddball-absent condition
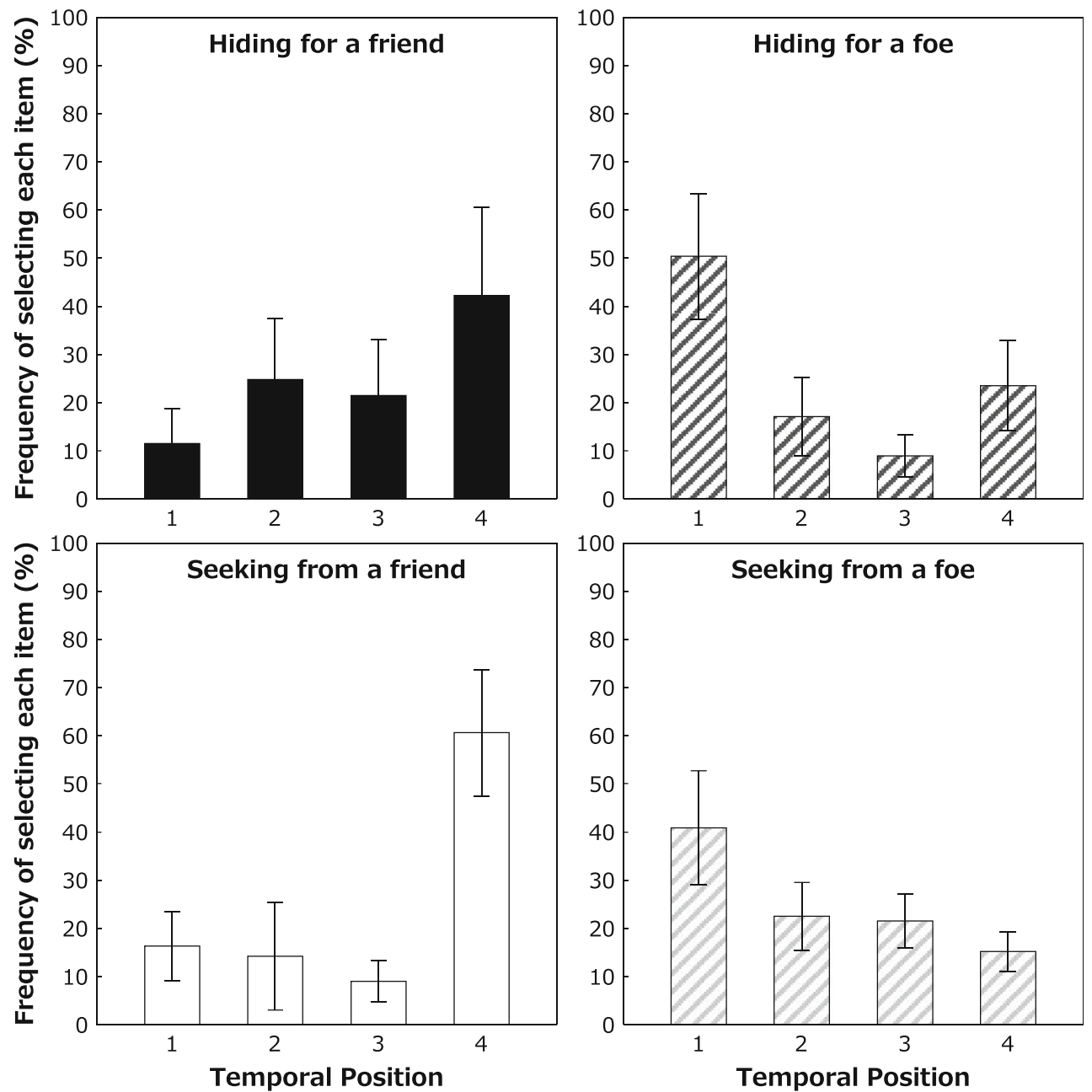

Fig. 3. Frequencies of selecting the items in each temporal position under the no-oddball condition according to each task scenario (hide or seek) and partner type (friend or foe) in Experiment 1. Error bars show 95\% confidence intervals

first and bottommost item would be least accessible. These differences in accessibility rather than temporal factors (e.g., presentation order) could be reflected in the selections for friends versus those for foes in both the hide and seek scenarios.

Although this accessibility-based explanation appears reasonable, other possibilities should also be considered. For example, these differences could be related to perceptual visibility because no items followed the last item. Prior to examining the accessibility hypothesis, Experiment 2 was designed and conducted to dismiss the perceptual visibility hypothesis by introducing visual masking such that that the masking item appeared at the end of the temporal sequence.

\section{Experiment 2}

Experiment 2 included visual masking to determine whether the results of Experiment 1, showing the selection of the last (or topmost stacked) item for friends in the non-oddball condition, was due to the spatial (e.g., three-dimensional) structure of the visual array or to perceptual visibility. The procedures used in Experiment 1 were also used in this experiment except that visual backward masking was applied to the last item in the temporal sequence. If the perceptual visibilities of the first and last items were critical for the pattern of selections observed in Experiment 1, then there should be a lower (or higher) frequency of the selection of the last (or first) item in both the hiding and finding scenarios in Experiment 2, as compared to Experiment 1, when the participants acknowledged that a hider or finder was a friend (or foe). This is because, in Experiment 2, the visibility or saliency of the last item should decrease following the application of visual backward masking (e.g., the suffix effect; Hu, Hitch, Baddeley, Zhang, \& Allen, 2014; Morton, Crowder, \& Prussin, 1971; Parmentier, Tremblay, \& Jones, 2004). However, if physical accessibility was critical for the selections observed in Experiment 1, then comparable results would be obtained in 
Experiment 2 because the spatial structure of the visual array remained unchanged.

Additionally, the duration of time it took to make a selection in Experiment 2 was recorded using a method similar to that of Anderson et al. (2014), who reported a diverging of cognitive processes for search and concealment based on data regarding decision time. Specifically, participants took longer to make a selection when hiding an item from a foe than when searching for an item from a foe in the oddball-present condition. These results suggest that participants will apply more complex strategies when hiding than when searching under the foe context. Thus, the recording and analyzing of decision times will further the current understanding of the cognitive processes underlying search versus those underlying concealment.

\section{Method}

Participants A new group of 40 undergraduate and graduate students (24 females; between 18 and 43 years of age) recruited from the participant pool at Hokkaido University participated in exchange for pay or course credit. Half of the participants (14 females; mean age $=21.1$ years) were randomly assigned to the hide scenario while the other half (10 females; mean age $=19.8$ years) was assigned to the seek scenario.

Apparatus, stimuli, design, and procedure The apparatus, stimuli, and design of Experiment 2 were the same as those used in Experiment 1. However, Experiment 2 included a visual random-dot mask that was the same size as the items in the sequence and which appeared in the center of the screen for $100 \mathrm{~ms}$ after the presentation of the sequence with no interstimulus interval. The direction from which an oddball slid in was counterbalanced across trials. Specifically, the majority of items in the sequence slid into view equally often from the bottom right (or bottom left) of the screen to the center of the screen, while one of the four items slid in from the opposite side (as an oddball item), if at all. Additionally, in Experiment 2 , the time it took from the offset of the visual mask to completion of the selection response was recorded even though the participants were not instructed to respond as quickly as possible.

\section{Results}

Oddball condition Figure 4 displays the mean frequencies of selecting the oddball item in each temporal position for scenario (hide vs. seek) and partner type (friend vs. foe). An ANOVA with scenario as a between-subjects factor and partner type as a within-subjects factor was conducted and revealed that the pattern of results obtained in Experiment 1 was replicated in Experiment 2. Specifically, there was a main effect of scenario $\left(F(1,38)=7.34, p=.01, \eta_{\mathrm{p}}{ }^{2}=.16\right)$, which indicates that the participants more frequently selected the oddball in the seek scenario than the hide scenario. Additionally, the main effect of partner type was significant $\left(F(1,38)=155.17, p<.001, \eta_{\mathrm{p}}^{2}=.80\right)$, which indicates that the participants more frequently selected the oddball for friends than for foes in both the hide and seek scenarios. The interaction between scenario and partner type was not significant $\left(F(1,38)=2.53, p=.12, \eta_{\mathrm{p}}^{2}=.06\right)$.

No-oddball condition Figure 5 displays the mean frequencies of selecting each of the four temporal positions for each partner type (friend or foe) and scenario (hide or seek). Chi-square tests indicated that the selections in the absence of the oddball were significantly biased by the temporal position when hiding for a friend (Fig. 5, top left; $\chi^{2}(3)=640.20, p<.001, w=$ 1.16). Specifically, the fourth item was most frequently selected among the items in the various temporal locations $(p s<$ $.001)$. The selection frequencies between the other pairs of locations did not differ $(p s>.70)$.

Next, similar Chi-square tests were conducted to assess the percentages of selections when hiding for a foe and revealed that these selections were significantly biased (Fig. 5, top right; $\left.\chi^{2}(3)=125.70, p<.01, w=0.51\right)$. Specifically, the first and second items were more frequently selected than the third and fourth items $(p s<.001)$. However, the selection frequencies between the first and second items and the third and fourth items did not differ ( $p s>.38$ ).

In the seek scenario from a friend, Chi-square tests indicated that the selections were significantly biased (Fig. 5, bottom left; $\left.\chi^{2}(3)=378.00, p<.001, w=0.89\right)$ such that the fourth item was selected most frequently among the items ( $p$ s $<$ $.001)$. The first item was more frequently selected than the second and third items $(p s<.01)$ but there was no difference between the second and third items $(p=.12)$. When seeking from a foe (Fig. 5, bottom right; $\chi^{2}(3)=115.08, p<.001, w=$ 0.49 ), the second item was most frequently selected among the items $(p s<.001)$ whereas the fourth item was least frequently selected $(p s<.002)$. Additionally, the first item was selected more frequently than the third and fourth items ( $p$ s $<$ $.03)$.

Completion times Experiment 2 also assessed the time required by each participant to make a decision, which was defined as the time from the offset of the mask to the time when a participant selected an item. The median completion times for each participant for each condition (scenario, partner type, and oddball) were calculated (each first trial in the first and second blocks was excluded from analyses of the completion times because these trials were interrupted by an experimenter for task instruction and, thus, we were unable to compare these trials with other trials); the group means of the median completion times are shown in Fig. 6. An ANOVA with scenario as a between-subjects factor and partner type 
oddball-present condition
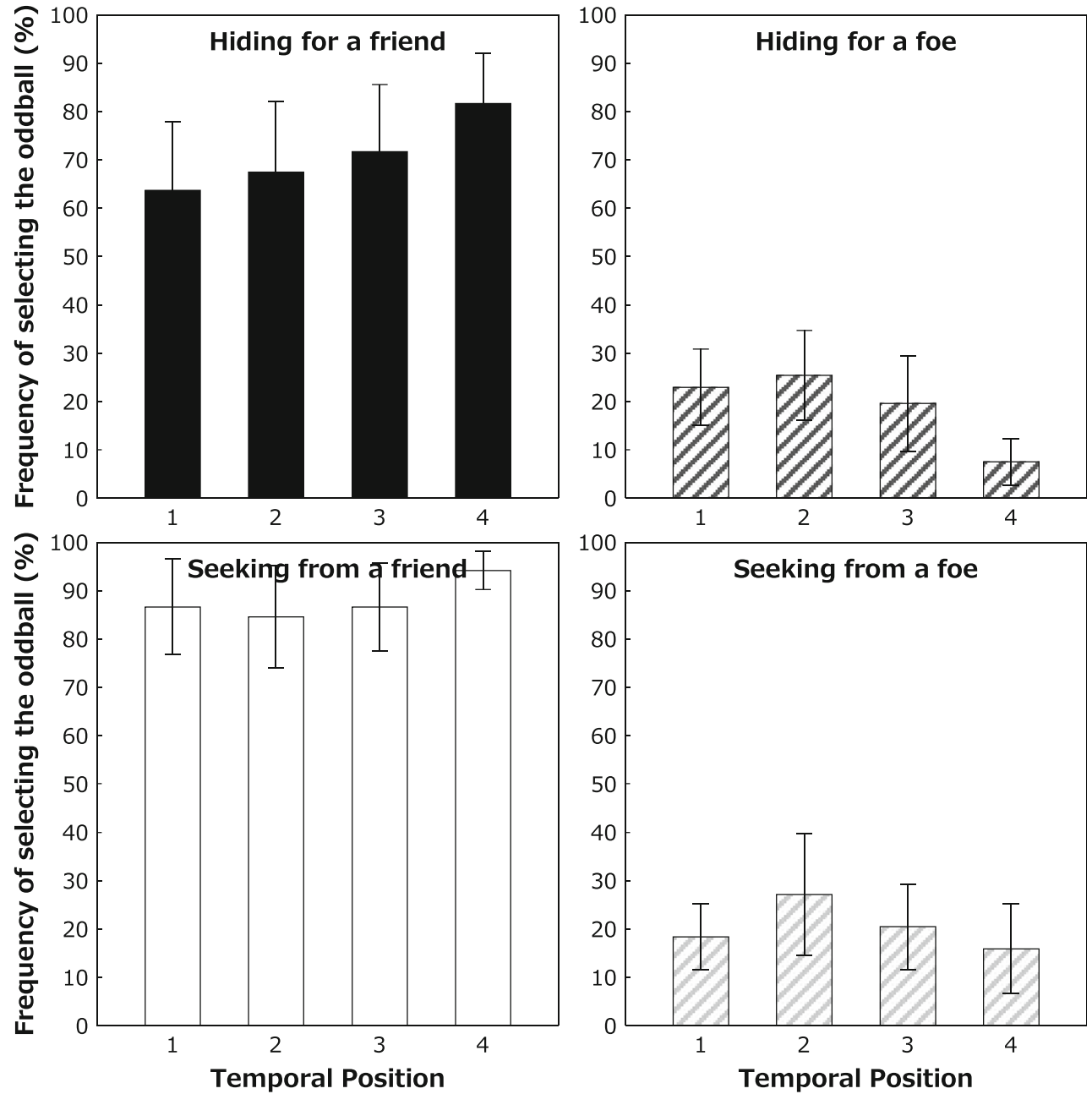

Fig. 4. Mean frequencies of selecting the oddball in each temporal position according to each task scenario (hide or seek) and partner type (friend or foe) in Experiment 2. Error bars show 95\% confidence intervals

and oddball as within-subjects factors revealed no main effects of task scenario $\left(F(1,38)=0.61, p=.44, \eta_{\mathrm{p}}^{2}=.02\right)$ or oddball $\left(F(1,38)=0.69, p=.41, \eta_{\mathrm{p}}^{2}=.02\right)$. However, the main effect of partner type was significant $(F(1,38)=19.15$, $p<.001, \eta_{\mathrm{p}}{ }^{2}=.34$ ), which indicates that completion times were shorter when selecting for friends than when selecting for foes.

Additionally, the interaction among these three factors was significant $\left(F(1,38)=9.04, p=.005, \eta_{\mathrm{p}}{ }^{2}=.20\right)$. An analysis of the simple-simple main effects of the oddball revealed that completion times were longer under the oddball-absent condition than under the oddball-present condition when searching for a friend $\left(F(1,19)=11.56, p=.003, \eta_{\mathrm{p}}^{2}=\right.$ .38). Moreover, an analysis of the simple-simple main effects of partner type revealed that completion times were longer for foes than friends when hiding $\left(F(1,19)=9.81, p=.006, \eta_{\mathrm{p}}{ }^{2}=\right.$ $.34)$ and seeking $\left(F(1,19)=24.47, p<.001, \eta_{\mathrm{p}}{ }^{2}=.56\right)$ in the oddball-present condition.

\section{Discussion}

Experiment 2 included a manipulation of visual masking to determine whether the preferential selection of the last (or topmost stacked) item for friends under the non-oddball condition in Experiment 1 was due to physical accessibility or visibility. The results were virtually identical to those of Experiment 1 and, thus, support the physical accessibility hypothesis. Specifically, under the oddball-absent condition, participants most frequently selected the topmost stacked item (e.g., last or fourth item) for friends regardless of whether they were hiding and seeking, whereas they selected the bottommost stacked items (e.g., first or second item) for foes. These results suggest that physical accessibility based on a threedimensional layout of the stacked items, such as perception of the ease in reaching for the last item, was critical for the selection rather than temporal factors (e.g., presentation order). 
oddball-absent condition
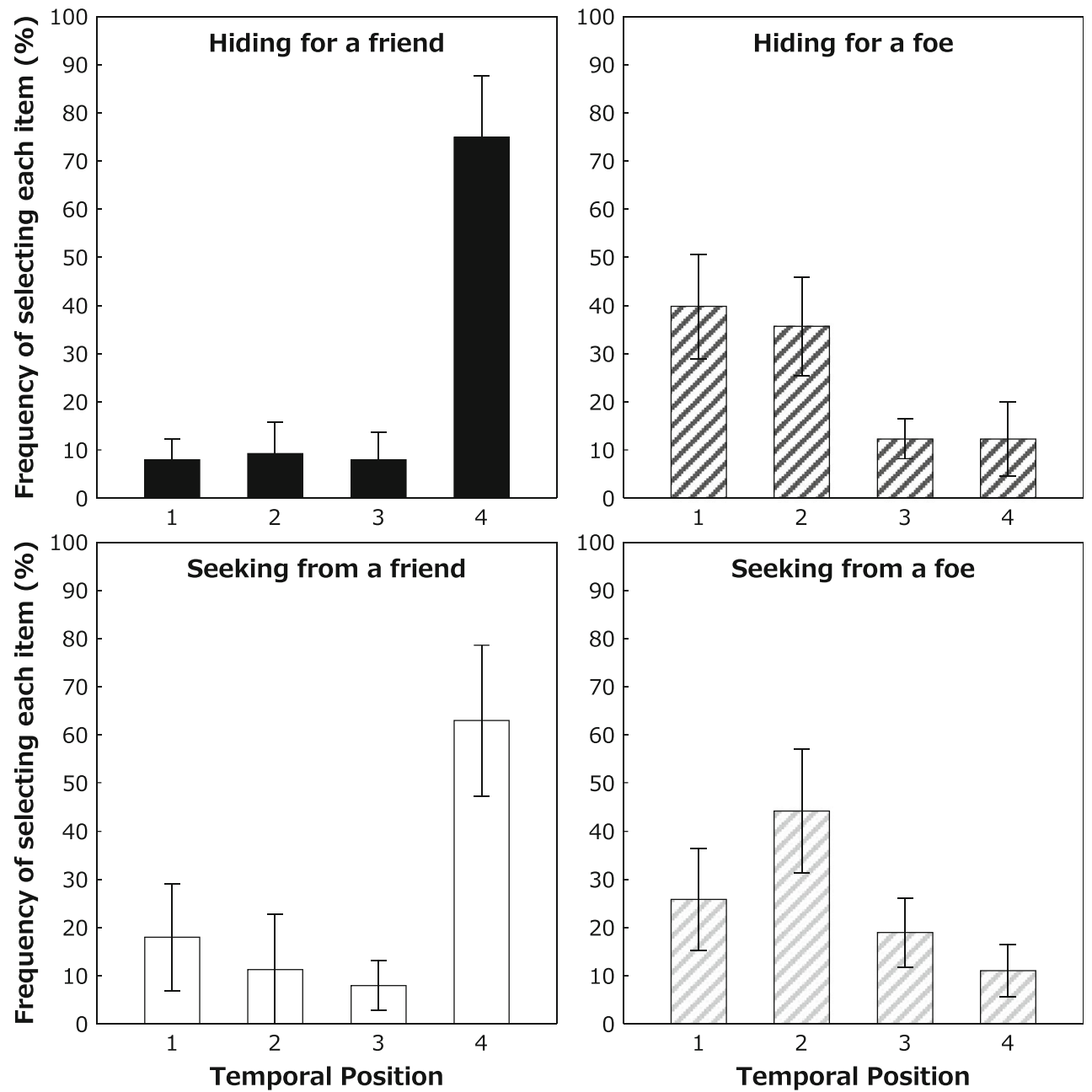

Fig. 5. Frequencies of selecting the items in each temporal position under the no-oddball condition according to each task scenario (hide or seek) and partner type (friend or foe) in Experiment 2. Error bars show 95\% confidence intervals

The perceptual visibility of the last item could not explain the present results. Interestingly, in Experiment 2, the frequencies of the last item being chosen for friends $(75.0 \%$ in the hide condition and $62.9 \%$ in the seek condition) were higher than those in Experiment 1 (42.3\% in the hide condition and $60.6 \%$ in the seek condition). These results indicate that the perceptual visibility of the last item in the absence of the visual mask was not critical when making a selection. Not surprisingly, when the oddball was present, the participants selected the oddball for friends but not for foes, which was consistent with the results of Experiment 1. Taken together, these findings reflect the fundamental principles underlying hiding and finding such that observers will hide or find items for/from friends (or foes) that would (or would not) attract attention.

The completion times when making a decision did not differ between the search and concealment conditions in the present study. This is in sharp contrast to the findings of Anderson et al. (2014) who reported that completion times in the concealment task are longer than those in the search task and suggested that this occurs because concealment is a more complex process than searching. It is possible that this inconsistency between studies is due to the number of items included in the temporal sequence. Anderson et al. (2014) and Street et al. (2018) both included 16 available items in the visual arrays and the completion times in those tasks (approximately $1000-1300 \mathrm{~ms}$ ) were longer than those in the present experiment (approximately 600-1100 ms). Additionally, the present procedure was designed to assess the case of sequentially presented items and the selections began at the onset of the first item and might not be finished until the offset of the last item in some trials. Nevertheless, longer completion times were observed in the foe condition than in the friend condition in the present study. These findings indicate that the participants utilized more complex strategies for foes than for friends, which is consistent with the results of previous studies showing that performance-based goals and internal 

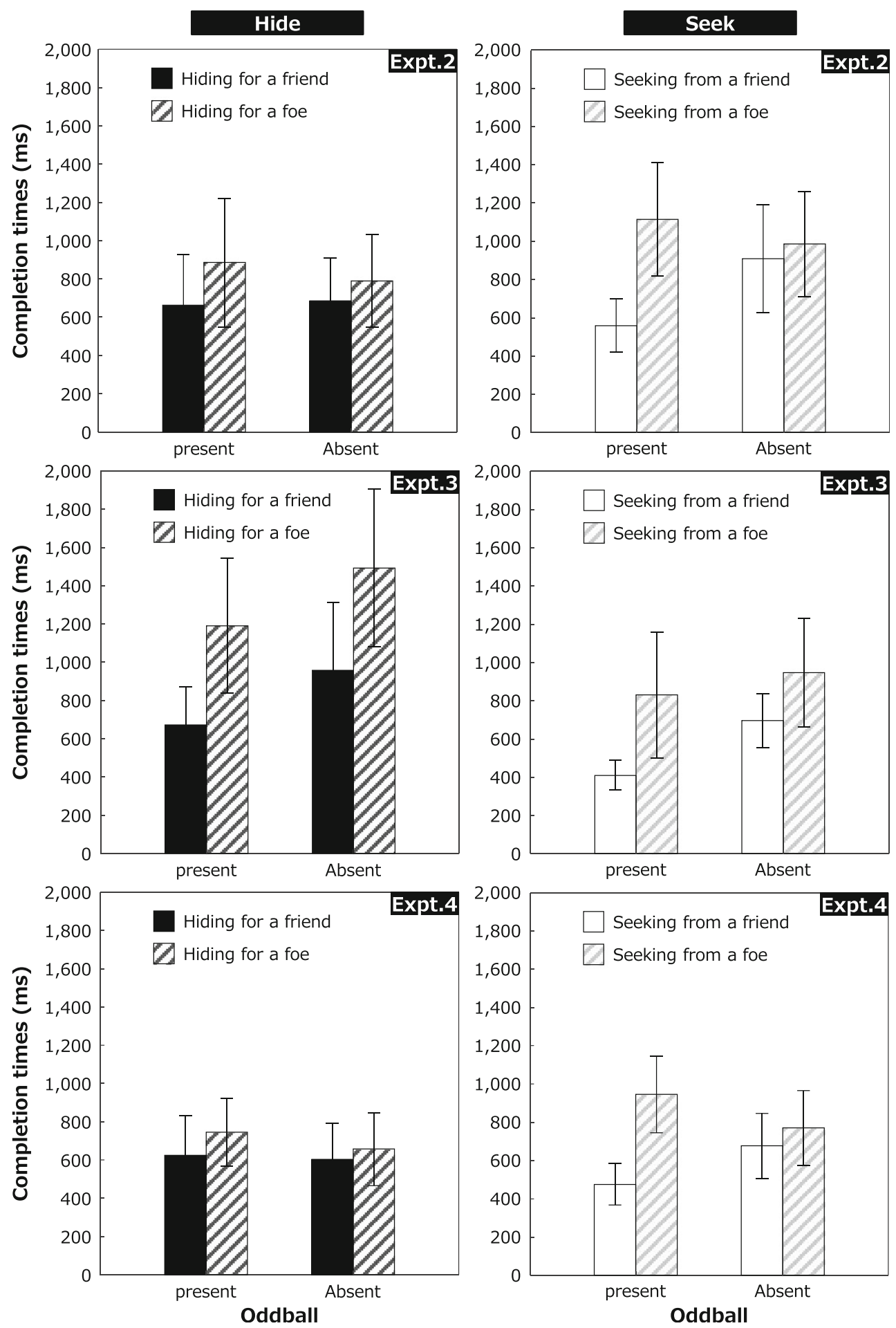

Fig. 6. Means of the median completion times according to each task scenario (hide or seek), partner type (friend or foe), and oddball (present or absent) in Experiments 2-4. Error bars show 95\% confidence intervals

motivations increase under competitive circumstances (e.g., Murayama \& Elliot, 2012; Tjosvold, Johnson, Johnson, \& Sun, 2006).

Thus far, the present results have revealed three major principles involved in the search and concealment of sequentially presented items. First, oddballs, if any, were chosen for friends and avoided for foes. Second, the last item was chosen for friends. Finally, the first item was chosen for foes. Thus, salient items were chosen for friends and avoided for foes regardless of the origin of saliency. In other words, the oddballs in the present study were defined as unique items that differed from the other items in terms of the direction from which they 
slid into the display; this directional difference made the items more salient compared to the others. When no oddballs were included in the sequence, the first and last items could potentially be salient because they were at the edge of the temporal sequence, i.e., the first item might have been salient because no items preceded it and the last item might have been salient because no items followed it. It should be noted that being the last item, rather than merely the fourth item, is critical. To test this interpretation, Experiment 3 included a manipulation of the number of items in the sequence.

\section{Experiment 3}

Experiment 3 examined the effects of the number of items in the presented sequence on search and concealment. In our opinion, the last item in the sequence is highlighted due to its position and, thus, becomes salient because no items follow it rather than the saliency being due to the item appearing as the fourth item, which represents the upper limits of working memory (Cowan, 2001). Nonetheless, the paradigms employed in Experiments 1 and 2 could not support the interpretation that an item being last and fourth confounded the results. Therefore, in Experiment 3, two more items were included in the sequence. If being presented as the last item in a temporal sequence was critical for the selection, then the last and sixth item would be more frequently selected for friends. Although unlikely, if being the fourth item was critical for the selection, then the fourth item should be more frequently chosen. Additionally, in the present study, it was expected that the number of the items in the sequence would not alter the salience of the initial items and, therefore, the initial items (e.g., first and/or second items) would be more frequently selected for foes.

\section{Method}

Participants A new group of 40 undergraduate and graduate students (16 females, between 18 and 25 years of age) recruited from the participant pool at Hokkaido University participated in exchange for pay or course credit. Half of the participants (eight females; mean age $=20.6$ years) were randomly assigned to the hide scenario and the other half (eight females; mean age $=20.2$ years) was assigned to the seek scenario.

Apparatus, stimuli, design, and procedure The apparatus, stimuli, and procedure in Experiment 3 were the same as those used in Experiment 2. However, unlike Experiment 2, the number of items in the sequence was increased from four to six; the duration of the sequence was $4500 \mathrm{~ms}$ ( $750 \mathrm{~ms}$ per card).

In total, the experimental session consisted of 12 blocks and 192 trials. Each block consisted of 16 trials, which included four trials under the oddball-absent condition and 12 trials under the oddball-present condition. The oddball was presented twice in each of the six possible temporal locations of the sequence. The orders of trials under the oddballpresent and -absent conditions were randomly determined within each block.

\section{Results}

Oddball condition Figure 7 displays the mean frequencies of selecting the oddball item in each temporal position for scenario (hide vs. seek) and partner type (friend vs. foe). An ANOVA with scenario as a between-subjects factor and partner type as a within-subjects factor revealed that the main effect of scenario was not significant $(F(1,38)=1.66, p=$ $\left..21, \eta_{\mathrm{p}}{ }^{2}=.04\right)$. However, the main effect of partner type was significant $\left(F(1,38)=156.26, p<.001, \eta_{\mathrm{p}}^{2}=.80\right)$, which indicates that participants more frequently selected the oddball for friends but not foes in both the hide and seek scenarios. The interaction between scenario and partner type was also significant $\left(F(1,38)=4.20, p=.05, \eta_{\mathrm{p}}^{2}=.10\right)$. An analysis of the simple-main effects revealed that the frequency of selecting an oddball in the friend context tended to decrease when participants engaged in the hide scenario relative to when they engaged in the seek scenario $(F(1,38)=4.10, p$ $\left.=.051, \eta_{\mathrm{p}}{ }^{2}=.10\right)$. However, no such trend was observed in the foe context $\left(F(1,38)=1.21, p=.28, \eta_{\mathrm{p}}^{2}=.03\right)$.

No-oddball condition Figure 8 displays the mean frequencies of selecting each one of the six temporal positions for partner type (friend or foe) and scenario (hide or seek). Chi-square tests revealed that the selections in the absence of the oddball were significantly biased by temporal position when hiding for a friend (Fig. 8, upper left; $\chi^{2}(5)=742.33, p<.001, w=$ 1.24 ), which indicates that the sixth item was most frequently selected among all items $(p s<.001)$. The first item was the second most frequently selected item relative to the others ( $p$ s $<.001$ ) but the selections of the items in the remaining temporal positions (i.e., second, third, fourth, and sixth items) did not differ $(p s>.07)$.

Similar Chi-square tests were applied to assess the probabilities of selections when hiding for a foe and revealed a significant effect of temporal position (Fig. 8, top right; $\chi^{2}$ $(5)=38.24, p<.001, w=0.28)$. Specifically, the first item was most frequently selected relative to other items $(p s<.05)$ and the second and third items were more frequently selected than the fifth item $(p s<.04)$. No differences were observed between the remaining pairs of items ( $p s>.06)$.

When seeking from a friend, Chi-square tests revealed that selections were significantly biased (Fig. 8, bottom left; $\chi^{2}(5)$ $=905.77, p<.001, w=1.37$ ) such that the sixth item was most frequently selected relative to the other items ( $p s<.001)$. The first item was the second most frequently selected item $(p s<$ 
oddball-present condition
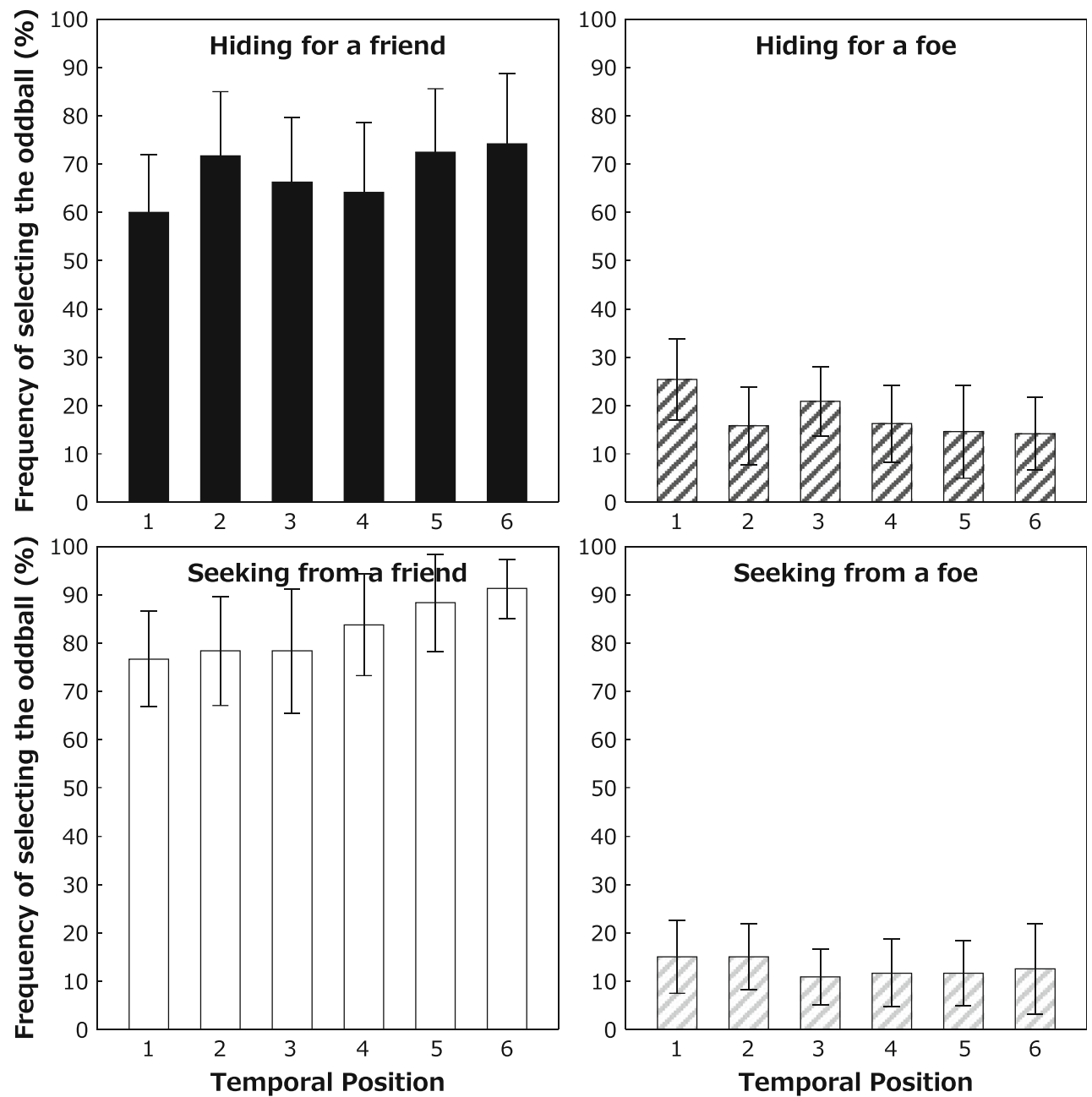

Fig. 7. Mean frequencies of selecting the oddball in each temporal position according to each task scenario (hide or seek) and partner type (friend or foe) in Experiment 3. Error bars show 95\% confidence intervals

$.003)$ and the third item was more frequently selected than the second or fifth items $(p s<.004)$. There were no differences in the selection frequencies between the remaining pairs ( $p s>$ .12).

Finally, the same Chi-square tests were applied to the seeking from a foe condition and revealed a significant effect of temporal position (Fig. 8, bottom right; $\chi^{2}(5)=36.97, p<$ $.001, w=0.28$ ). Specifically, the first and second items were more frequently selected than the other items $(p s<.05)$, the third item was more frequently selected than the sixth item ( $p$ $=.05)$, and the fifth item was more frequently selected than the sixth item $(p=.02)$. There were no differences in selection frequencies between the other pairs of comparisons ( $p s>.21)$.

Completion times The middle panels of Fig. 6 show the group means of the median completion times in Experiment 3. An ANOVA with scenario as a between-subjects factor and partner type and oddball as within-subjects factors revealed a marginally significant main effect of scenario $(F(1,38)=$
3.96, $p=.054, \eta_{\mathrm{p}}{ }^{2}=.09$ ), which indicates that the completion times when hiding were longer than when seeking. Significant main effects were also found for oddball $(F(1,38)=17.74, p$ $\left.<.001, \eta_{\mathrm{p}}{ }^{2}=.32\right)$ and partner type $(F(1,38)=28.61, p<.001$, $\left.\eta_{\mathrm{p}}{ }^{2}=.43\right)$. The former result indicated that the completion times in the oddball-present condition were shorter than in the oddball-absent condition. The latter result indicated that the completion times were shorter during selections for friends than for foes. No interaction effects were observed among the factors for completion times $\left(F_{\mathrm{s}}(1,38)<1.44, p \mathrm{~s}>.24, \eta_{\mathrm{p}}{ }^{2}<\right.$ $.04)$.

\section{Discussion}

In Experiment 3, when the sequence did not contain an oddball, the last (sixth) item was more frequently selected for friends in both scenario types. This result indicates that the last item in the temporal sequence was critical during selection for a friend rather than the fourth item being most critical. 
oddball-absent condition
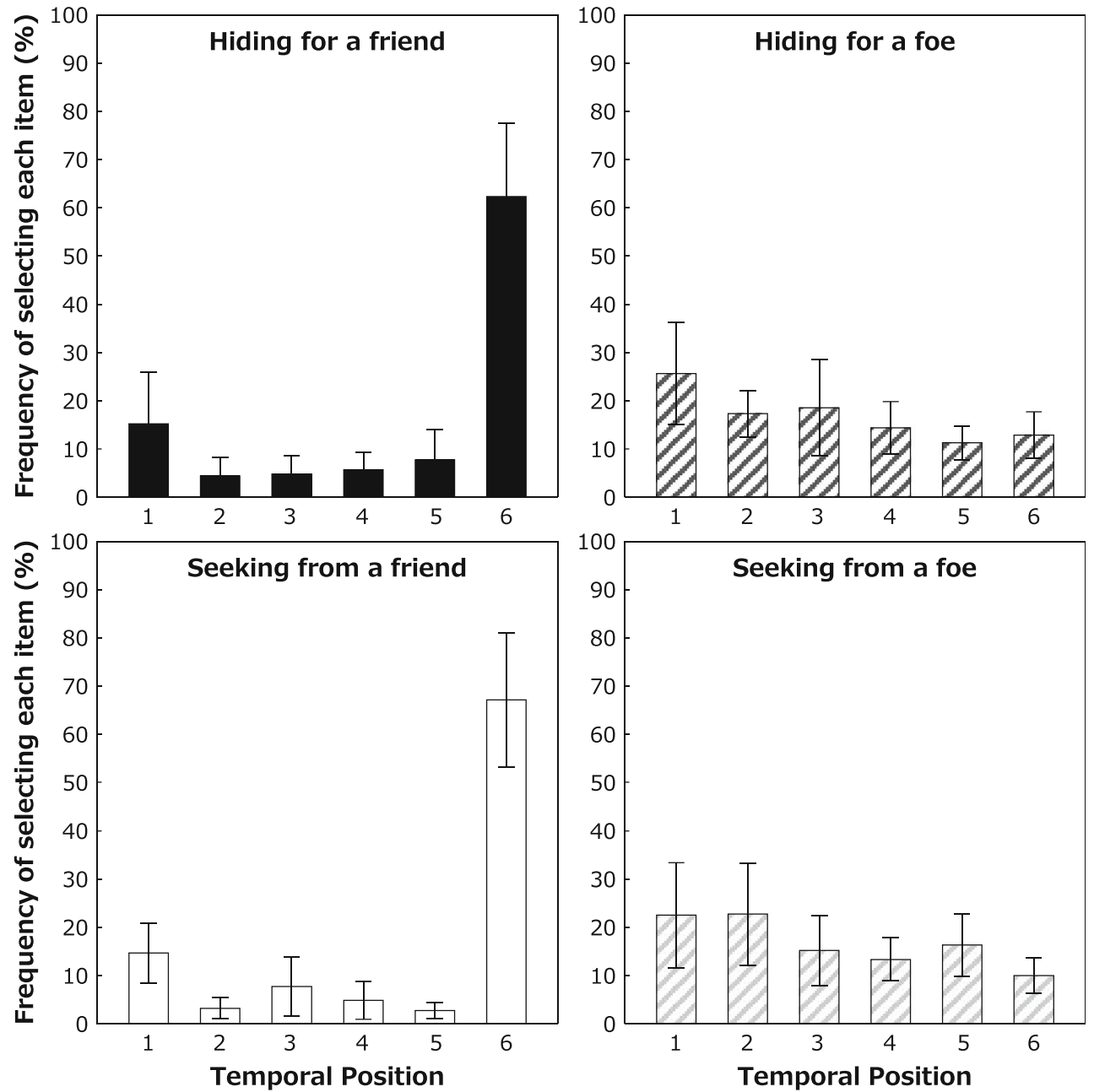

Fig. 8. Frequencies of selecting the items in each temporal position under the no-oddball condition according to each task scenario (hide or seek) and partner type (friend or foe) in Experiment 3. Error bars show 95\% confidence intervals

Additionally, the initial items (i.e., first and second items) were more frequently selected for foes under the no-oddball condition, which was identical to the results obtained in Experiments 1 and 2. In all three experiments, the saliencies of the initial items were similar regardless of the number of the items in the sequence. Taken together, these results support the physical accessibility hypothesis based on a three-dimensional layout of the stacked items rather than temporal factors. However, for friends, the initial (first) items were selected relatively more frequently under both scenarios, which indicates that the participants continued to employ strategies that assumed that the first item would attract attention relative to other items. As expected, the results from the oddball-present condition were identical to the results of the previous experiments in that participants selected the oddball for friends but not foes, demonstrating the fundamental principles underlying hiding and finding.

The present results for completion times in the task scenarios differed from those observed in Experiment 2.
Specifically, in Experiment 3, the completion times in the hide scenario were longer than those in the seek scenario whereas these differences were not observed in Experiment 2. This finding is consistent with those of Anderson et al. (2014) and suggests that hiding involves more complex strategies than seeking. In contrast, effects similar to those observed in Experiment 2 were obtained for partner type in Experiment 3. Specifically, there was a longer completion time for foes than for friends, which is likely to indicate that the participants used more complex strategies for foes than for friends. This pattern of results is consistent with those of previous studies (e.g., Murayama \& Elliot, 2012; Tjosvold et al., 2006) in that performance-based goals or internal motivations increase under competitive circumstances. Finally, there were longer completion times in the non-oddball condition than the oddball condition, which indicates that the fixed strategies used in the oddball condition led to faster decisions because the selections in this condition were dominant. 


\section{Experiment 4}

The final experiment included a manipulation of the direction of the stacking order to determine whether perceptual accessibility would be susceptible to the stacked order of the items. Specifically, the items in Experiment 4 were stacked downward whereas the items in Experiments 1-3 were stacked in an upward direction; therefore, the first (or last) items were the topmost (or bottommost) stacked items in Experiment 4. If the topmost stacked item (e.g., first item) was frequently selected for friends and the bottommost stacked item (e.g., fourth item) was frequently selected for foes, then the explanation based on physical accessibility would be supported regardless of the order of the stack.

\section{Method}

Participants A new group of 40 undergraduate and graduate students (13 females, between 18 and 24 years of age) recruited from the participant pool at Hokkaido University participated in exchange for pay or course credit. Half of the participants (seven females; mean age $=19.8$ years) were randomly assigned to the hide scenario and the other half (six females; mean age $=20.6$ years) was assigned to the seek scenario.

Apparatus, stimuli, design, and procedure In Experiment 4, the apparatus, stimuli, and design were the same as those used in Experiment 2. However, whereas each card was stacked upwards in Experiments 1-3, the participants indicated where they would hide or find an item in a temporal sequence of cards in which each card was stacked downwards in Experiment 4. Using this type of visualization, it was not possible to visually recognize new cards stacked in the bottommost layer because they closely overlapped. To avoid ambiguity during interpretation of the stacked order, the participants were explicitly instructed before the experiment that the newly presented card would be placed underneath the bottommost card of the previously stacked items.

\section{Results}

Oddball condition Figure 9 displays the mean frequencies of selecting the oddball item in each temporal position for partner type (friend vs. foe) and task scenario (hide vs. seek). An ANOVA with task scenario as a between-subjects factor and partner type as a within-subjects factor revealed a significant main effect of task scenario $\left(F(1,38)=13.08, p<.001, \eta_{\mathrm{p}}{ }^{2}=\right.$ .26 ), which indicates that the participants more frequently selected the oddball in the seek scenario than the hide scenario. Additionally, the main effect of partner type was significant ( $F$ $\left.(1,38)=107.89, p<.001, \eta_{\mathrm{p}}^{2}=.74\right)$, which indicates that participants selected the oddball in both the hide and seek scenarios for friends but not foes.
The interaction between task scenario and partner type was also significant $\left(F(1,38)=9.08, p=.005, \eta_{\mathrm{p}}{ }^{2}=.19\right)$. An analysis of the simple-main effects revealed that the frequency of selecting an oddball in the friend context significantly decreased when participants engaged in the hide scenario compared to when they engaged in the seek scenario $(F(1,38)=$ $\left.12.87, p<.001, \eta_{\mathrm{p}}{ }^{2}=.25\right)$. However, no such effect of task scenario was observed in the foe condition $(F(1,38)=0.30, p$ $\left.=.59, \eta_{\mathrm{p}}^{2}=.01\right)$.

No-oddball condition Figure 10 displays the mean frequencies of selecting one of the four temporal positions according to partner type (friend vs. foe) and task scenario (hide vs. seek). Chi-square tests revealed that the selections in the absence of the oddball were significantly biased by temporal position when hiding for a friend (Fig. 10, top left; $\chi^{2}(3)=77.22, p$ $<.001, w=0.40)$. Specifically, the first item was most frequently selected compared to the other items $(p s<.001)$ and the second item was more frequently selected than the third and fourth items $(p s<.008)$. The selection frequencies between the third and fourth items did not differ $(p=.07)$.

Similar Chi-square tests were applied to assess the probabilities of selections when hiding for a foe and revealed a significant effect of temporal position (Fig. 10, top right; $\chi^{2}$ (3) $=14.55, p<.01, w=0.17)$. Specifically, the fourth item was more frequently selected than the second and third items $(p s<.03)$ but the selections between the first and fourth items did not differ $(p=.40)$. The first item was more frequently selected than the third item $(p=.03)$. However, the selection frequencies between the first and second items $(p=.21)$ and between the second and third items did not differ $(p=.39)$.

In the seek scenario from a friend, Chi-square tests revealed that the selections were significantly biased (Fig. 10, bottom left; $\left.\chi^{2}(3)=324.28, p<.001, w=0.82\right)$, which indicates that the first item was more frequently selected than the other items ( $p \mathrm{~s}<.001)$. Additionally, the fourth item was more frequently selected than the second and third items $(p s<.001)$ but there was no difference in the selection frequencies between the second and third items $(p=.41)$.

Finally, the same Chi-square tests were applied to the seeking from a foe condition and revealed a significant effect of temporal position (Fig. 10, bottom right; $\chi^{2}(3)=32.92, p<$ $.001, w=0.26$ ), which indicates that the second item was more frequently selected than the fourth item $(p<.001)$. However, the selection of the second item did not differ from those of the first and third items $(p s>.10)$. The fourth item was selected least frequently among all items $(p s<.001)$.

Completion times The completion times in Experiment 4 were compared across conditions; Fig. 6 (bottom) shows the group means of the median completion times. An ANOVA with scenario as a between-subjects factor and partner type and oddball as within-subject factors revealed no main effects of 
oddball-present condition
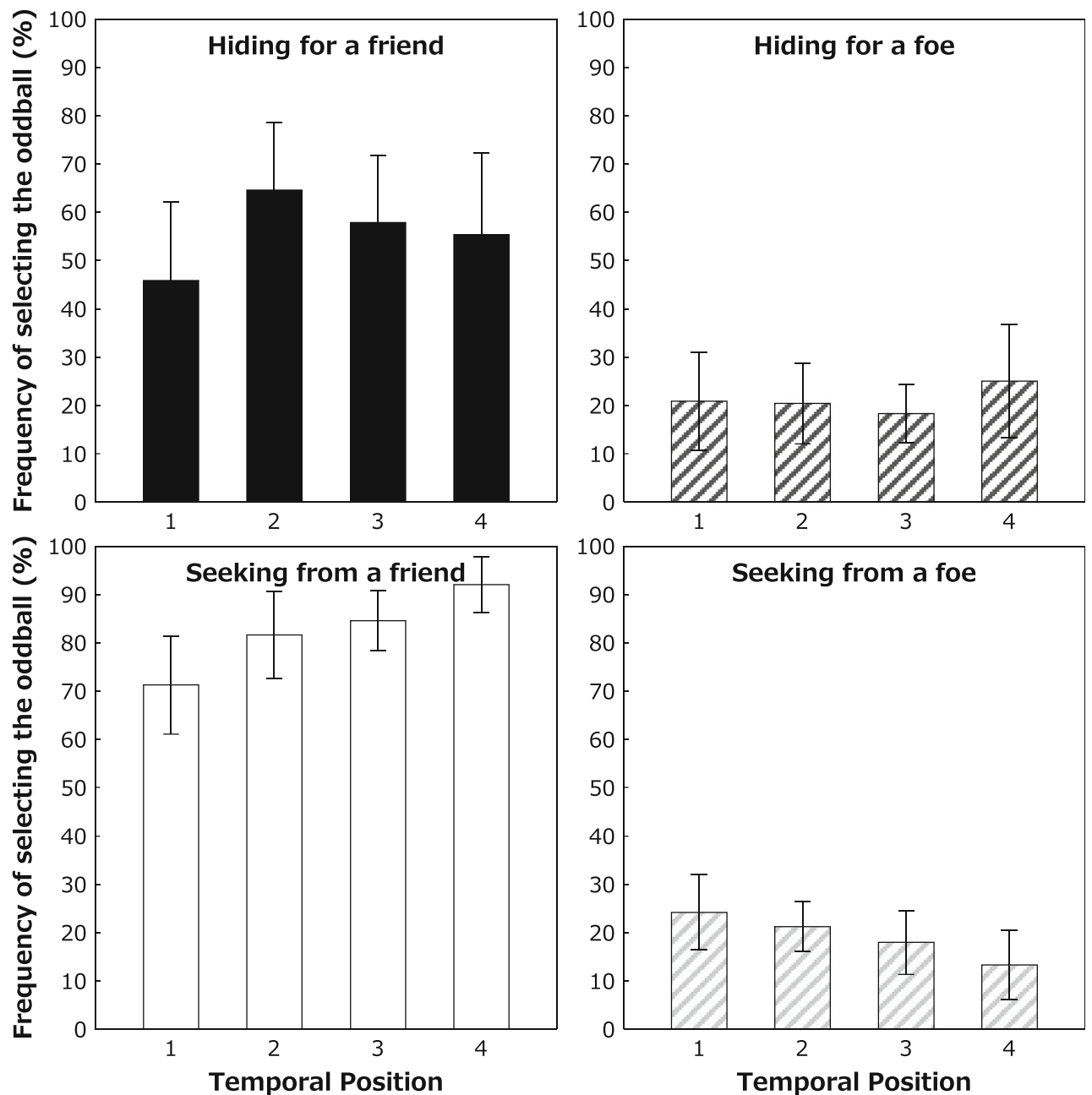

Fig. 9. Mean frequencies of selecting the oddball in each temporal position according to each task scenario (hide or seek) and partner type (friend or foe) in Experiment 4. Error bars show 95\% confidence intervals

scenario $\left(F(1,38)=0.26, p=.61, \eta_{\mathrm{p}}^{2}=.01\right)$ and oddball $(F$ $\left.(1,38)=0.46, p=.50, \eta_{\mathrm{p}}^{2}=.01\right)$. The main effect of partner type was significant $\left(F(1,38)=17.38, p<.001, \eta_{\mathrm{p}}^{2}=.31\right)$, which indicates that the response times were shorter for selections for friends than for foes. The interaction among the three factors was also significant $\left(F(1,38)=6.98, p=.01, \eta_{\mathrm{p}}{ }^{2}=\right.$ $.16)$ and an analysis of the simple-simple main effects of the oddball factor revealed that the completion times were longer on trials in the oddball-absent condition than in the oddballpresent condition when searching for items for a friend $(F(1$, 19) $=6.86, p=.02, \eta_{\mathrm{p}}{ }^{2}=.27$ ) whereas the completion times were shorter on trials in the oddball-absent condition than in the oddball-present condition when searching for items for a foe $\left(F(1,19)=8.25, p=.01, \eta_{\mathrm{p}}{ }^{2}=.30\right)$. Moreover, an analysis of the simple-simple main effect of partner type revealed that the completion times were longer for a foe than for a friend when seeking $\left(F(1,19)=28.90, p<.001, \eta_{\mathrm{p}}{ }^{2}=.60\right)$ in the oddball-absent condition.

\section{Discussion}

The results of Experiment 4 supported the physical accessibility hypothesis only when hiding and seeking items for/from a friend. Specifically, when an oddball was absent, the topmost stacked item (i.e., the item presented first in the sequence) was more frequently selected for friends regardless of whether the scenario was hiding or seeking, which reflects the perception of ease when reaching for items. However, perceptual accessibility did not predict the behaviors of the participants when hiding and seeking for/from a foe. The fourth item (i.e., the bottommost stacked item) should have been most frequently selected relative to the other items (e.g., first item) if the participants chose items based on physical accessibility. However, the present results revealed that the first and fourth items were more frequently selected when hiding for a foe.

Moreover, the present results differed from those of previous experiments when seeking from a foe. In the present 
oddball-absent condition
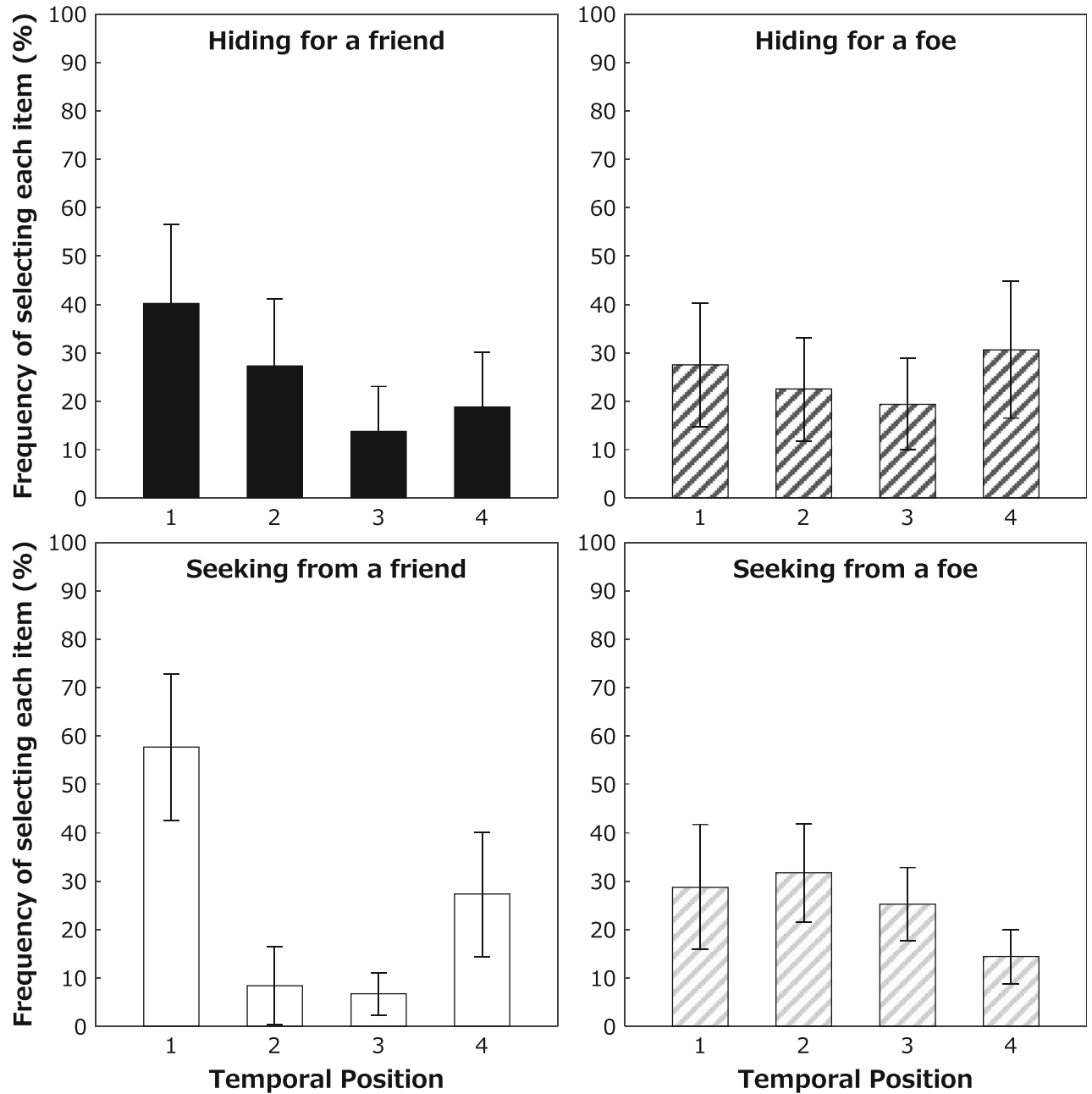

Fig. 10. Frequencies of selecting the items in each temporal position under the no-oddball condition according to each task scenario (hide or seek) and partner type (friend or foe) in Experiment 4. Error bars show 95\% confidence intervals

study, the top-layered items (i.e., the first and second items) were more frequently selected than the bottommost stacked item (i.e., the fourth item). Intuitively, the first item should attract strong attention because it remained in view and, thus, was continually attended to during the presentation of the temporal sequence. One possible explanation for this finding is that perceptual accessibility was applied to the concealment and search strategies for friends. In contrast, observers would apply these strategies based on temporal order, such as temporal remoteness, because the first (or second) item was frequently selected for foes regardless of the stacked order. Therefore, two different strategies appear to have been applied based on partner type, i.e., observers applied search and concealment strategies for friends based on spatial factors, such as physical accessibility, whereas they applied strategies based on temporal factors, such as remoteness in time, for foes.

In the oddball-present condition, participants most frequently selected the oddball for friends whereas they avoided selecting the oddball for foes, suggesting that there are fundamental principles associated with hiding and finding. The completion time results in Experiment 4 were almost the same as those obtained in Experiment 2. Additionally, longer completion times were observed in the foe context than in the friend context, which suggests that the participants applied more complex strategies for foes than for friends.

\section{General discussion}

The present study examined the temporal principles involved in hiding and finding using a revised hide-find paradigm (Anderson et al., 2014; Street et al., 2018). Throughout the four experiments conducted in this study, observers were more likely to select the oddball (when it was present) for friends but not for foes in both the hiding and seeking scenarios. This strategy is identical to the strategy that is employed during search and concealment in the spatial (or two-dimensional) domain (Anderson et al., 2014; Street et al., 2018). In the 
present situations of temporal and three-dimensional search and concealment, fundamental strategies for hiding and finding were applied such that observers selected salient items/ positions more frequently for friends and non-salient items/ positions for foes. In other words, based on their intuitions about the difficulties of searching and the ease of discovering a target item, the observers probably believed that the oddball would attract the attention of a supposed friend, who could be a finder or hider, but they avoided choosing the singleton for a foe.

However, in the present study, the strategies for hiding and searching differed. The frequencies of selecting an oddball for friends in the hide scenario were lower than those in the seek scenario. Observers applied more complex strategies when hiding than when finding because concealment behavior was applied to knowledge regarding search difficulty (Anderson et al., 2014; Smilek et al., 2009). However, when an oddball was present, observers required longer decision times for foes than for friends in both task scenarios. Taken together, these results indicate that different cognitive processes were involved in making a selection depending on partner type (i.e., social context: friend or foe). It is possible that the observers estimated the finder's allocation of attention in two steps. In the first step, they expected that the finder's attention would be captured by the oddball because the oddball was reasonably salient. This intuition should be supported by participants' impressions obtained from their viewing of the sequence and can be assigned as a metacognitive estimation of friends' searching and hiding behaviors. In the second step, the observers would estimate foes' searching and hiding behaviors based on this intuitive estimation so that the salient items would be avoided. The involvement of this second stage was reflected in the completion times as the effect of partner type (friend vs. foe) when the oddball was present. Thus, it is possible that when participants were mentally simulating the trajectories of another's attention during searching and hiding, the presence of an oddball made this estimation easier due to the common sense idea that the oddball should drive the initial allocation of the other's attention towards it, regardless of scenario and partner type. Therefore, the frequencies of selecting items were straightforward and consistent across the experiments when an oddball was present.

In line with the two steps of attentional allocation, the present choice behaviors seem to be related to the reflection effect (e.g., Kahneman \& Tversky, 1979) in which individuals are essentially likely to be risk-averse during a risky choice, leading to gains, and to be risk-seeking during a risky choice, leading to losses, in a game such as the present task. There is an asymmetric relationship between gains and losses and, thus, it is assumed that observers switched such choice modes according to partner type. In other words, observers are likely to select a particular target position conservatively and consistently in the friend context and contemplate various choices in the foe context to avoid loss. Therefore, the results of the completion times showed that longer times were required in the foe context relative to in the friend context. The idea is also identical to the high consistency of selection frequencies in the friend context and varied choices in the foe context relative to the friend context.

Importantly, the present study was primarily concerned with temporal search and concealment strategies when an oddball was absent and, thus, two specific alternative hypotheses were tested. First, if the spatial principles involved in hiding and finding, in which participants prefer edge items for friends and central items for foes, are based on natural intuitions regarding search difficulties (e.g., Anderson et al., 2014; Smilek et al., 2009) or serial order effects (primacy and recency effects) and are critical for selection strategies, then the first and last items would be selected for friends and the other items would be selected for foes. Second, if physical accessibility based on the spatial (e.g., three-dimensional) structures of the stacked items (Solman et al., 2012, 2014; Street et al., 2018) rather than temporal factors (e.g., presentation order), which convey the perception of ease or difficulty when reaching for items, was critical for the pattern of the present results, then the top-layered (or bottom-layered) items would be selected for friends (or foes). The present results supported the latter hypothesis in the case of hiding and searching for the target for/from a friend. Specifically, the observers hid or found the topmost stacked items (e.g., last items in Experiments 1-3 and first item in Experiment 4) for/ from a friend. These results suggest that the observers estimated the selection of a supposed friend as a hider or finder based on the spatial structure of the spatiotemporal sequence so that the ease of picking the item was affected.

In contrast, the present data do not support the physical accessibility hypothesis when hiding and seeking a target for/from a foe. In the present study, observers more frequently selected the items that appeared relatively early (e.g., first and second items) in the temporal sequence when hiding and finding for/from a foe. This selection tendency occurred regardless of whether physical accessibility was represented by the stacked direction. More specifically, in Experiment 4, the items were stacked in a downward direction so that the latter items in the sequence became less accessible than the earlier items, whereas the items in Experiments 1-3 were stacked in an upward direction so that the latter items became more accessible. If the perceptual accessibility-based strategies had been observed in Experiment 4, then the last items to be placed in the bottommost positions would have been more frequently selected. Thus, it is possible that search and concealment strategies might dramatically differ depending on partner type. In other words, participants may adopt strategies based on physical accessibility when they interact with a friend whereas they may adopt strategies based on temporal remoteness for a foe. It should be noted that there was no 
difference between the frequencies for selecting the first and last items when hiding even though the tendency for selecting an earlier item remained the same as for finding in Experiment 4. Moreover, the completion times for making a decision were longer in the hide scenario relative to the seek scenario throughout the four experiments in the present study. Therefore, physical accessibility and temporal remoteness are insufficient explanations of the present results. As a result, additional factors involved in the metacognitive estimation for hiding for a foe should be assessed in future studies.

Experiments 2 and 3 in the present study individually examined and dismissed minor factors that could have contributed to the effects of partner type and task scenario on the selection of items. In Experiment 2, the possibility that the more frequent selection of the last item for friends in the oddball-absent condition was due to perceptual visibility was excluded by demonstrating that this biased selection remained even when the last item was visually masked. That is, the present results support the physical accessibility account. In Experiment 3, the possibility that the present results were specific to the four-item sequence used in the study was excluded by increasing the number of items from four to six. The subsequent results in the present study were virtually identical to those of previous experiments, which suggests the generality of the present findings. However, in the present study, increasing the number of the items in the sequence influenced the time to make a selection because the completion times in Experiment 3 (e.g., selections from six possible items) were longer than those in the other experiments (e.g., selections from four possible items). More specifically, the completion times in the hide scenario from a foe in Experiment 3 were longer when the oddball was absent. These data are consistent with the second stage account of estimation that utilizes conscious processes that are limited in terms of capacity. In contrast, the completion times in both the hide and seek scenarios from a friend in Experiment 3 were similar to those in Experiments 2 and 4, when the oddball was present. These results support the first stage account stating that participants would estimate searching and hiding positions on the basis of unconscious processes (e.g., intuitive impressions) regardless of the number of the possible items.

The present study revealed metacognitive estimation in the interpersonal situation and was an initial step toward identifying the essential mechanism of search and concealment underlying various aspects of daily life. For example, in a shopping mall, several products or services are sequentially provided to customers. In legal courts, the presentation order of several pieces of evidence might be critical for decision making by a jury. Such explorations would be useful to studies of persuasive communication. It is possible to examine the effect of presentation order on our choices in realistic situations. Previous studies have explored spatial search and concealment strategies in complex scenes (e.g., room; Legge et al.,
2012; Talbot et al., 2009). Although the effect of spatial positioning of items on purchase is well known (e.g., center-stage effect), the visual array used in the present study did not include a definite central position because the numbers of presented items were even in all experiments. This is in sharp contrast with previous research on spatial searchers showing a well-known bias for choosing the central position. For example, during product choice, consumers prefer a product in a central position due to the belief that this product is the most popular (Valenzuela \& Raghubir, 2009) or because they tend to pay attention to the product in the center (Atalay, Bodur, \& Rasolofoarison, 2012). Future research should examine whether this center-stage effect would apply to search and concealment strategies in the present task.

The hide-find paradigm (Anderson et al., 2014; Street et al., 2018) was originally developed as a measurement tool for examining theory of mind (Baron-Cohen, Leslie, \& Frith, 1985; Premack \& Woodruff, 1978) in adults. However, previous studies have also used this paradigm to explore the development of search and concealment in children (Cornell \& Heth, 1986; Somerville \& Capuani-Shumaker, 1984; Wellman, Somerville, \& Haake, 1979) as well as food hoarding and cache protection in animals (Clayton \& Dickinson, 1998; Dally, Emery, \& Clayton, 2004, 2005; Garamszegi \& Eens, 2004; Krebs, Sherry, Healy, Perry, \& Vaccarino, 1989) by focusing on cognitive abilities such as memory and executive function. Theory of mind involves the ability to accurately assess others' beliefs, intentions, desires, and knowledge and is essential for search and concealment behaviors (Anderson et al., 2014; Street et al., 2018) because search items are usually hidden by hiders so that finders will (or will not) find it. That is, finders or hiders need to estimate the intentions of another. The accurate assessment of others' intentions leads to efficient search and concealment and vice versa. Based on the present results, it is possible to conclude that the present task engaged theory of mind because the hiding and finding positions were strategic under all circumstances (e.g., task scenarios, partner types, and presence or absence of the oddball). Furthermore, the present study revealed that these strategies can be flexibly employed based on a variety of circumstances, including partner type (friend or foe) and task scenario (hide or seek). Thus, observers can assess partners' intentions by simulating strategies that the partner would adopt or in which an opponent would attend to salient sequential positions or an oddball.

However, based on the present findings, it remains unclear how accurately observers can access others' intentions because the present task simply estimated hiding and finding positions without feedback regarding success (or failure) of the search and concealment. Hence, as a unique feature of the present study, the accuracy of the intentions between the task scenarios (hide or find), depending on condition (partner type or oddball) and temporal position of the oddball, was 
estimated by conducting the following three steps in each experiment: (1) all selection data were analyzed and randomly aligned in each experimental condition, (2) hit rates of the selected positions between the hide and seek scenarios were calculated according to the same partner type and oddball conditions, and (3) steps 1 and 2 were repeated five times because this number of iterations produces a mean hit rate that never changes even if a greater number of iterations is implemented due to a small variance of the mean hit rate. The hit rate represents the accuracy rates between finders' and hiders' intentions in the friend context due to sharing the same goal whereas it represents the accuracy rates of finders' and hiders' intentions in the foe context due to the presence of different goals. For example, if the hit rate was above chance in the friend context, then the observers in each task scenario could accurately estimate mutual intentions. If the hit rate was equal to chance in the foe context, then observers in the seek scenario could not accurately estimate hiders' intentions, or, the observers in the hide scenario could accurately estimate finders' intentions.

Figure 11 displays the mean hit rates according to partner type (friend vs. foe) and oddball (oddball-present vs. oddballabsent). Not surprisingly, in the oddball-present condition, the hit rates in the friend context were above chance in all experiments, which means that both finders and hiders could accurately estimate the intentions of each other. However, in the oddball-present condition, the hit rates in the foe context were equal to chance in all experiments, which means that finders could not accurately estimate hiders' intentions and that hiders successfully concealed a target. Importantly, these results were similar to the hit rates in the oddball-absent condition. In other words, both finders and hiders could accurately estimate each other's intentions when they acknowledged that the partner was a friend even if the oddball was absent. However, finders could not accurately estimate hiders' intentions, while hiders could successfully conceal a target. These results suggest that common strategies were used in the friend context whereas hiders had an advantage in the foe context. The former results were identical to the results of the selection frequencies in the present study and were likely to be due to the use of simpler (e.g., more intuitive) strategies for friends relative to foes. In contrast, the latter results might have been caused by randomness of selection. For example, a visual inspection revealed that the selections at particular temporal locations (i.e., the topmost items, such as the last items in Experiments 1-3 and the first item in Experiment 4) were dominant in the friend context whereas there were no such trends observed in the foe context. Interestingly, the selections were actually strategic for hiders because placing a target in random positions without regularity leads to increased difficulty when searching (e.g., Wilke et al., 2015). Similarly, such scattered hiding or searching is not limited to human adults and is also observed in different populations (e.g., children; Cornell \& Heth, 1986) and species (e.g., food hording animals; Brodin, 2010; Vander Wall, 1990). These behaviors require advanced memory function and developmental stage and seem to be related to theory of mind abilities. The present findings may introduce new opportunities for examining theory of mind by comparing hit rates between selected positions in the contexts of search and concealment.

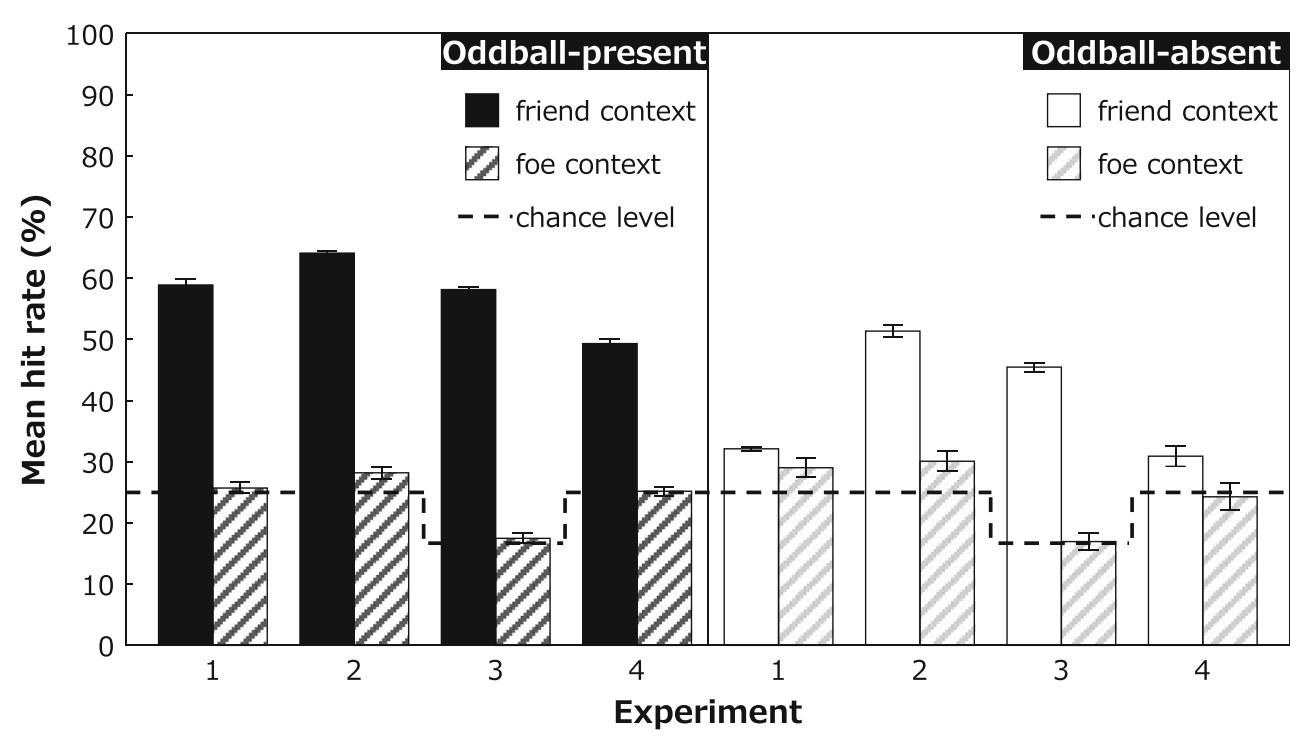

Fig. 11. Mean hit rates between the selected items for task scenario (hide and seek) according to partner type (friend and foe), oddball (present and absent), and temporal position of the oddball in Experiments 1-4. Under the oddball-present condition, the results were collapsed with the temporal position. Error bars show one standard deviation and dashed lines show chance levels $(25.0 \%$ in Experiments 1, 2, and 4; $16.7 \%$ in
Experiment 3). If the partner type was friend, then there was a higher chance that both the hide and seek groups would accurately select the temporal position. If the partner type was foe, then there was a higher chance that the hide group would fail the selection whereas the seek group would succeed 
Acknowledgements We would like to thank Rie Kitade for help with data collection. This study was supported by Grants-in-Aid for Scientific Research from the Japan Society for the Promotion of Science (17H02648) to JK and Grant-in-Aid for JSPS Fellows from the Japan Society for the Promotion of Science (17J04401) to MI.

Open practices statement The data and significant program code will be made available after acceptance via the Open Science Framework (https://osf.io/4dtb9/), and none of the experiments were preregistered.

\section{References}

Anderson, G. M., Foulsham, T., Nasiopoulos, E., Chapman, C. S., \& Kingstone, A. (2014). Hide and seek: The theory of mind of visual concealment and search. Attention, Perception, \& Psychophysics, 76, 907-913. DOI: https://doi.org/10.3758/s13414-014-0675-6

Ariga, A., \& Yokosawa, K. (2008). Attentional awakening: Gradual modulation of temporal attention in rapid serial visual presentation. Psychological Research, 72, 192-202. https://doi.org/10.1007/ s00426-006-0100-4

Atalay, A. S., Bodur, H. O., \& Rasolofoarison, D. (2012). Shining in the center: Central gaze cascade effect on product choice. Journal of Consumer Research, 39, 848-866. DOI: https://doi.org/https://doi. org $/ 10.1086 / 665984$

Awh, E., Belopolsky, A. V., \& Theeuwes, J. (2012). Top-down versus bottom-up attentional control: A failed theoretical dichotomy. Trends in Cognitive Sciences, 16, 437-443. DOI: https://doi.org/ https://doi.org/10.1016/j.tics.2012.06.010

Baron-Cohen, S., Leslie, A. M., \& Frith, U. (1985). Does the autistic child have a "theory of mind"? Cognition, 21, 37-46. DOI: https:// doi.org/https://doi.org/10.1016/0010-0277(85)90022-8

Benjamini, Y., \& Hochberg, Y. (1995). Controlling the false discovery rate: A practical and powerful approach to multiple testing. Journal of the Royal Statistical Society: Series B (Methodological), 57, 289 300. https://doi.org/10.1111/j.2517-6161.1995.tb02031.x

Brainard, D. H. (1997). The psychophysics toolbox. Spatial Vision, 10, 433-436. DOI: https://doi.org/10.1163/156856897X00357

Brodin, A. (2010). The history of scatter hoarding studies. Philosophical Transactions of the Royal Society, B: Biological Sciences, 365, 869881. DOI: https://doi.org/https://doi.org/10.1098/rstb.2009.0217

Carrasco, M. (2011). Visual attention: The past 25 years. Vision Research, 51, 1484-1525. DOI: https://doi.org/https://doi.org/10.1016/j. visres.2011.04.012

Clayton, N. S., \& Dickinson, A. (1998). Episodic-like memory during cache recovery by scrub jays. Nature, 395, 272-274. DOI: https:// doi.org/https://doi.org/10.1038/26216

Cornell, E. H., \& Heth, C. D. (1986). The spatial organization of hiding and recovery of objects by children. Child Development, 57, 603615. DOI: https://doi.org/10.2307/1130339

Coull, J. T., Frith, C. D., Büchel, C., \& Nobre, A. C. (2000). Orienting attention in time: Behavioural and neuroanatomical distinction between exogenous and endogenous shifts. Neuropsychologia, 38, 808-819. DOI: https://doi.org/https://doi.org/10.1016/s00283932(99)00132-3

Cowan, N. (2001). The magical number 4 in short-term memory: A reconsideration of mental storage capacity. Behavioural Brain Research, 24, 87-114. DOI: https://doi.org/https://doi.org/10.1017/ S0140525X01003922

Dally, J. M., Emery, N. J., \& Clayton, N. S. (2004). Cache protection strategies by western scrub-jays (Aphelocoma californica): Hiding food in the shade. Proceedings of the Royal Society of London. Series B: Biological Sciences, 271, S387-S390. DOI: https:// doi.org/https://doi.org/10.1098/rsbl.2004.0190
Dally, J. M., Emery, N. J., \& Clayton, N. S. (2005). Cache protection strategies by western scrub-jays, Aphelocoma californica: Implications for social cognition. Animal Behaviour, 70, 12511263. DOI: https://doi.org/https://doi.org/10.1016/j.anbehav.2005. 02.009

Garamszegi, L. Z., \& Eens, M. (2004). The evolution of hippocampus volume and brain size in relation to food hoarding in birds. Ecology Letters, 7, 1216-1224. DOI: https://doi.org/https://doi.org/10.1111/ j.1461-0248.2004.00685.x

Grenfell-Essam, R., \& Ward, G. (2012). Examining the relationship between free recall and immediate serial recall: The role of list length, strategy use, and test expectancy. Journal of Memory and Language, 67, 106-148. DOI: https://doi.org/10.1016/j.jml.2012.04.004

Hommel, B. (2015). The theory of event coding (TEC) as embodiedcognition framework. Frontiers in Psychology, 6, 1318. DOI: https://doi.org/https://doi.org/10.3389/fpsyg.2015.01318

Hu, Y., Hitch, G. J., Baddeley, A. D., Zhang, M., \& Allen, R. J. (2014). Executive and perceptual attention play different roles in visual working memory: Evidence from suffix and strategy effects. Journal of Experimental Psychology: Human Perception and Performance, 40, 1665-1678. DOI: https://doi.org/https://doi.org/ 10.1037/a0037163

Kahneman, D., \& Tversky, A. (1979). Prospect Theory: An analysis of decision under risk. Econometrica, 47, 263-291.

Kleiner M, Brainard D, Pelli D (2007). What's new in Psychtoolbox-3? Perception, 36, ECVP Abstract Supplement.

Kranczioch, C., \& Bryant, D. (2011). Attentional awakening, resource allocation and the focus of temporal attention Neuroreport, 22, 161165. DOI: https://doi.org/10.1097/WNR.0b013e3283438b76

Krebs, J. R., Sherry, D. F., Healy, S. D., Perry, V. H., \& Vaccarino, A. L. (1989). Hippocampal specialization of food-storing birds. Proceedings of the National Academy of Sciences, 86, 1388-1392. DOI: https://doi.org/https://doi.org/10.1073/pnas.86.4.1388

Lamy, D., Leber, A. B., \& Egeth, H. E. (2012). Selective attention. In A. F. Healy, \& R. W. Proctor (Eds.), Comprehensive handbook of psychology. Experimental psychology, Vol. 4. (pp. 265-294). New York: Wiley (4th ed., editor-in-chief I. B. Weiner).

Legge, E. L. G., Spetch, M. L., Cenkner, A., Bulitko, V., Anderson, C., Brown, M., \& Heth, D. (2012). Not all locations are created equal: Exploring how adults hide and search for objects. PLoS One, 7, e36993. DOI: https://doi.org/https://doi.org/10.1371/journal.pone. 0036993

Liesefeld, H. R., Moran, R., Usher, M., Müller, H. J., \& Zehetleitner, M. (2016). Search efficiency as a function of target saliency: The transition from inefficient to efficient search and beyond. Journal of Experimental Psychology: Human Perception and Performance, 42, 821-836. DOI: https://doi.org/https://doi.org/10.1037/ xhp0000156

Martens, S., \& Wyble, B. (2010). The attentional blink: Past, present, and future of a blind spot in perceptual awareness. Neuroscience \& Biobehavioral Reviews, 34, 947-957. DOI: https://doi.org/https:// doi.org/10.1016/j.neubiorev.2009.12.005

Mento, G., \& Tarantino, V. (2015). Developmental trajectories of internally and externally driven temporal prediction. PLoS One, 10, e0135098. DOI: https://doi.org/https://doi.org/10.1371/journal. pone.0135098

Morton, J., Crowder, R. G., \& Prussin, H. A. (1971). Experiments with the stimulus suffix effect. Journal of Experimental Psychology, 91, 169-190. DOI: https://doi.org/https://doi.org/10.1037/h0031844

Murayama, K., \& Elliot, A. J. (2012). The competition-performance relation: A meta-analytic review and test of the opposing processes model of competition and performance. Psychological Bulletin, 138, 1035-1070. DOI: https://doi.org/https://doi.org/10.1037/a0028324

Murdock Jr, B. B. (1962). The serial position effect of free recall. Journal of Experimental Psychology, 64, 482-488. DOI: http://dx.doi.org/ https://doi.org/10.1037/h0045106 
Parmentier, F. B., Tremblay, S., \& Jones, D. M. (2004). Exploring the suffix effect in serial visuospatial short-term memory. Psychonomic Bulletin \& Review, 11, 289-295. DOI: https://doi.org/https://doi.org/ 10.3758/bf03196572

Pastukhov, A., Vonau, V., Stonkute, S., \& Braun, J. (2013). Spatial and temporal attention revealed by microsaccades. Vision Research, 85 , 45-57. DOI: https://doi.org/https://doi.org/10.1016/j.visres.2012. 11.004

Pelli, D. G. (1997). The VideoToolbox software for visual psychophysics: Transforming numbers into movies. Spatial Vision, 10, 437-442. DOI: https://doi.org/https://doi.org/10.1163/156856897X00366

Pratt, J., \& Abrams, R. A. (1994). Action-centered inhibition: Effects of distractors on movement planning and execution. Human Movement Science, 13, 245-254. DOI: https://doi.org/https://doi.org/10.1016/ 0167-9457(94)90039-6

Premack, D., \& Woodruff, G. (1978). Does the chimpanzee have a theory of mind? Behavioral and Brain Sciences, 1, 515-526. DOI: https:// doi.org/https://doi.org/10.1017/S0140525X00076512

Raymond, J. E., Shapiro, K. L., \& Arnell, K. M. (1992). Temporary suppression of visual processing in an RSVP task: An attentional blink? Journal of Experimental Psychology: Human Perception and Performance, 18, 849-860. DOI: https://doi.org/https://doi.org/10. 1037//0096-1523.18.3.849

Rohenkohl, G., Coull, J. T., \& Nobre, A. C. (2011). Behavioural dissociation between exogenous and endogenous temporal orienting of attention. PLoS One, 6, e14620. DOI: https://doi.org/https://doi.org/ 10.1371/journal.pone.0014620

Shin, Y. K., Proctor, R. W., \& Capaldi, E. J. (2010). A review of contemporary ideomotor theory. Psychological Bulletin, 136, 943-974. DOI: https://doi.org/https://doi.org/10.1037/a0020541

Smilek, D., Weinheimer, L., Kwan, D., Reynolds, M., \& Kingstone, A. (2009). Hiding and finding: The relationship between visual concealment and visual search. Attention, Perception, \& Psychophysics, 71, 1793-1806. DOI: https://doi.org/https://doi.org/10.3758/APP. 71.8 .1793

Solman, G. J., Cheyne, J. A., \& Smilek, D. (2012). Found and missed: Failing to recognize a search target despite moving it. Cognition, 123, 100-118. DOI: https://doi.org/10.1016/j.cognition.2011.12. 006

Solman, G. J., Hickey, K., \& Smilek, D. (2014). Comparing target detection errors in visual search and manually-assisted search. Attention, Perception, \& Psychophysics, 76, 945-958. DOI: https://doi.org/10. 3758/s13414-014-0641-3
Somerville, S. C., \& Capuani-Shumaker, A. (1984). Logical searches of young children in hiding and finding tasks. British Journal of Developmental Psychology, 2, 315-328. DOI: https://doi.org/ https://doi.org/10.1111/j.2044-835X.1984.tb00939.x

Street, C. N., Bischof, W. F., \& Kingstone, A. (2018). Perspective taking and theory of mind in hide and seek. Attention, Perception, \& Psychophysics, 80, 21-26. DOI: https://doi.org/https://doi.org/10. 3758/s13414-017-1446-y

Talbot, K. J., Legge, E. L., Bulitko, V., \& Spetch, M. L. (2009). Hiding and searching strategies of adult humans in a virtual and a real-space room. Learning and Motivation, 40, 221-233. DOI: https://doi.org/ https://doi.org/10.1016/j.lmot.2009.01.003

Tipper, S. P., Lortie, C., \& Baylis, G. C. (1992). Selective reaching: Evidence for action-centered attention. Journal of Experimental Psychology: Human Perception and Performance, 18, 891-905. DOI: https://doi.org/https://doi.org/10.1037//0096-1523.18.4.891

Tjosvold, D., Johnson, D. W., Johnson, R. T., \& Sun, H. (2006). Competitive motives and strategies: Understanding constructive competition. Group Dynamics: Theory, Research, and Practice, 10, 87-89. DOI: http://dx.doi.org/https://doi.org/10.1037/10892699.10.2.87

Valenzuela, A., \& Raghubir, P. (2009). Position-based beliefs: The centerstage effect. Journal of Consumer Psychology, 19, 185-196. DOI: https://doi.org/https://doi.org/10.1016/j.jcps.2009.02.011

Vander Wall, S. B. (1990). Food hoarding in animals. University of Chicago Press, Chicago, Illinois, USA.

Wellman, H. W., Somerville, S. C., \& Haake, R. J. (1979). Development of search procedures in real-life spatial environments. Developmental Psychology, 15, 530-542. DOI: http://dx.doi.org/ https://doi.org/10.1037/0012-1649.15.5.530

Wilke, A., Minich, S., Panis, M., Langen, T. A., Skufca, J. D., \& Todd, P. M. (2015). A game of hide and seek: Expectations of clumpy resources influence hiding and searching patterns. PLoS One, 10, e0130976. DOI: https://doi.org/https://doi.org/10.1371/journal. pone. 0130976

Wolfe, J. M., \& Horowitz, T. S. (2017). Five factors that guide attention in visual search. Nature Human Behaviour, 1, 0058. DOI: https:// doi.org/https://doi.org/10.1038/s41562-017-0058

Publisher's note Springer Nature remains neutral with regard to jurisdictional claims in published maps and institutional affiliations. 